\title{
Aluminum-clad Spent Nuclear Fuel Engineering Scale Drying Experiment Design
}

Travis Knight ${ }^{*}$, Nathaniel Cooper ${ }^{*}$, Matthew Shalloo*, Tanvir Farouk*, Yi Wang*, Jamil Khan*, and Rebecca Smith ${ }^{\dagger}$ - Editor

*University of South Carolina ${ }^{\dagger}$ Materials Science \& Engineering, Idaho National Laboratory

August 2019

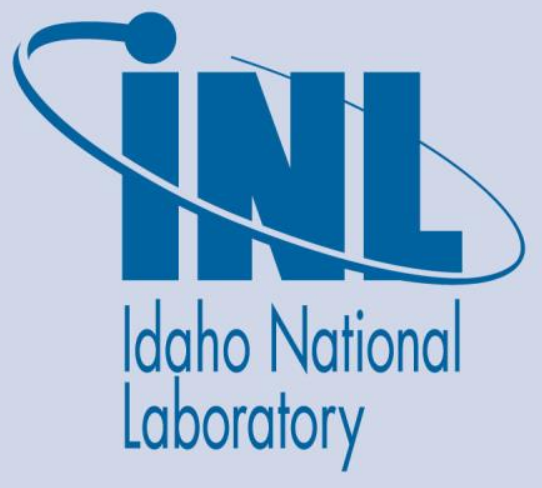

The INL is a U.S. Department of Energy National Laboratory operated by Battelle Energy Alliance 


\section{DISCLAIMER}

This information was prepared as an account of work sponsored by an agency of the U.S. Government. Neither the U.S. Government nor any agency thereof, nor any of their employees, makes any warranty, expressed or implied, or assumes any legal liability or responsibility for the accuracy, completeness, or usefulness, of any information, apparatus, product, or process disclosed, or represents that its use would not infringe privately owned rights. References herein to any specific commercial product, process, or service by trade name, trade mark, manufacturer, or otherwise, does not necessarily constitute or imply its endorsement, recommendation, or favoring by the U.S. Government or any agency thereof. The views and opinions of authors expressed herein do not necessarily state or reflect those of the U.S. Government or any agency thereof. 
INL/EXT-19-56017

Revision 0

\title{
Aluminum-clad Spent Nuclear Fuel Engineering Scale Drying Experiment Design
}

\author{
Travis Knight*, Nathaniel Cooper*, Matthew Shalloo*, Tanvir Farouk*, Yi Wang ${ }^{\star}$, \\ Jamil Khan*, and Rebecca Smith ${ }^{\dagger}$ - Editor \\ *University of South Carolina \\ †Materials Science \& Engineering, Idaho National Laboratory
}

August 2019

Idaho National Laboratory ASNF Extended Dry Storage Project

Idaho Falls, Idaho 83415

http://www.inl.gov

Prepared for the

U.S. Department of Energy

Office of Environmental Management

Under DOE Idaho Operations Office

Contract DE-AC07-05ID14517 



\section{SUMMARY}

The purpose of this document is to provide the technical specifications for the Engineering Scale Design for the drying tests of aluminum-clad spent nuclear fuel (ASNF). The engineering scale design is to accommodate both forced helium drying (FHD) as well as vacuum drying. The experiments will employ mock ASNF assemblies with a limited number of chemically treated aluminum plates to simulate the aluminum hydroxides found on ASNF. The goal here is to understand the transformation that may occur in plates including the loss of chemisorbed water and changes in morphology. Physiosorbed and bulk water found in experiments will be dried in the process and the effect on drying operations noted. Decay heat will be simulated in one assembly using a custom designed resistance heating element. A typical radial arrangement of assemblies will be employed using a modified Type 1A Basket design. For the chamber/canister, a single assembly layer with full radial dimension will be employed. Modifications to the standard canister design and configuration include the addition of a siphon tube to enable recirculation of hot gas for forced helium drying. A ring of ports/flanges are added near the top of the chamber to accommodate the feedthroughs for instrumentation and power needed for the experiment and data collection. Four viewports are added to the main section of the chamber with two in line with one of the fuel assembly and siphon tube. The other two viewports are on the opposite side of the chamber. The purpose here is to provide the option of thermal imaging in addition to the nearly four dozen thermocouples available inside the chamber. Modeling of the chamber, basket, and mock ASNF assemblies was conducted to estimate temperature distributions throughout the chamber during forced helium drying and over the anticipated drying period. This modeling was used as input to decisions on the Engineering Scale Design. Work on modeling continues in the period during setup and testing to develop preliminary drying models. Analysis of experimental results will later be used to validate these and subsequent models. 



\section{ACKNOWLEDGEMENTS}

The authors wish to express their appreciation for the recommendations and assistance from Mike Connolly, Josh Jarrell, and Alex Abboud of Idaho National Laboratory, John Griffiths and Garrick Stafford of Holtec, and Bob Sindelar of Savannah River National Laboratory, in the design of this experiment and to acknowledge that funding for this work has been provided under the Department of Energy Idaho Operations Office, Contract DE-AC07-05ID14517 with Battelle Energy Alliance, LLC. 



\section{CONTENTS}

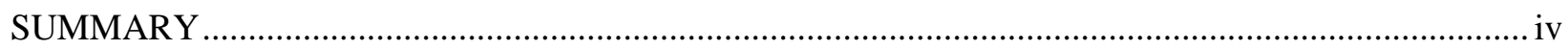

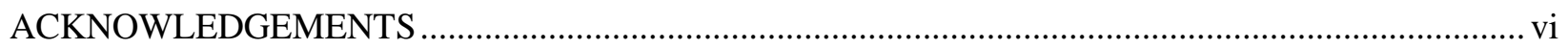

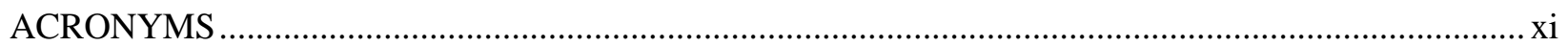

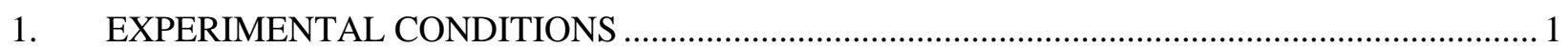

2. CFD SIMULATIONS AND EXPERIMENTAL OPERATION ……........................................... 1

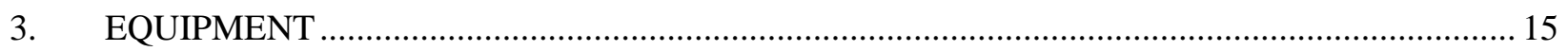

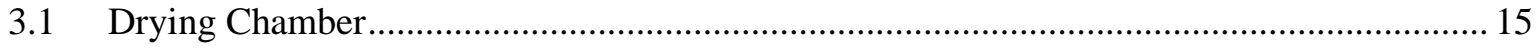

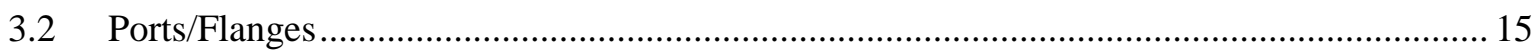

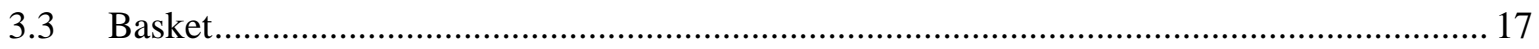

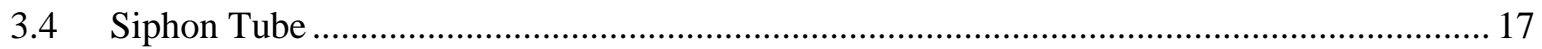

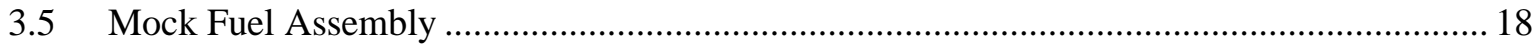

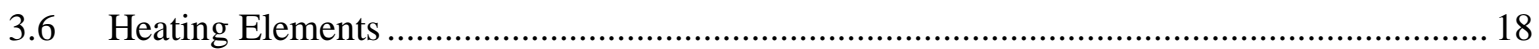

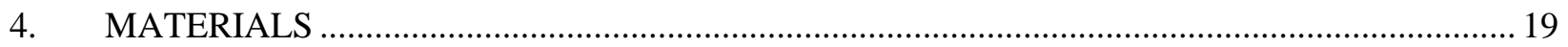

4.1 Chemically Treated Plates......................................................................................... 19

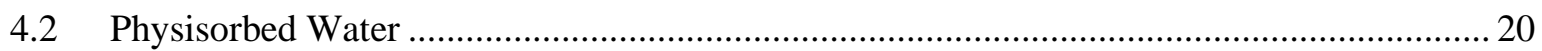

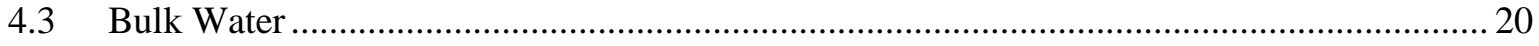

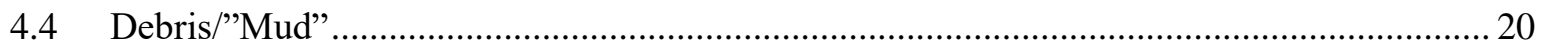

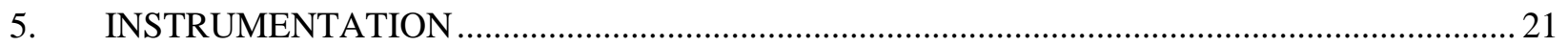

$5.1 \quad$ Temperature Measurement......................................................................................... 21

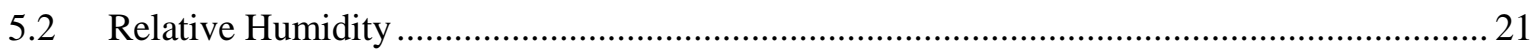

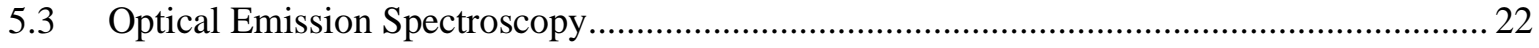

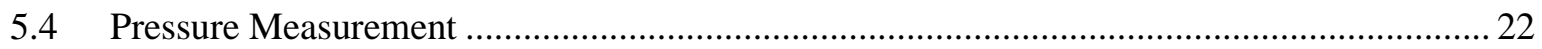

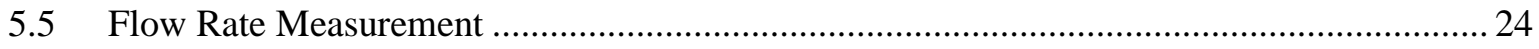

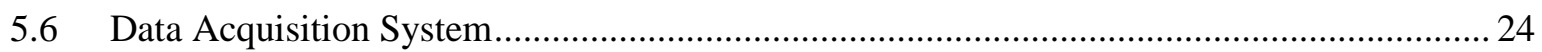

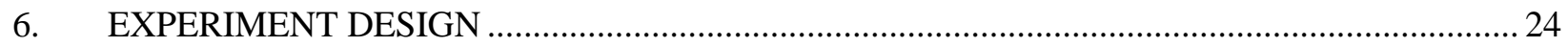

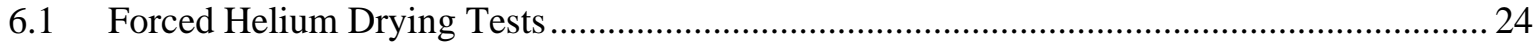

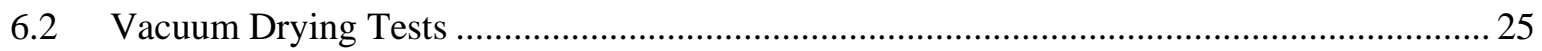

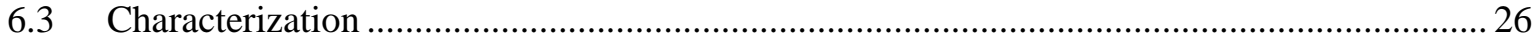

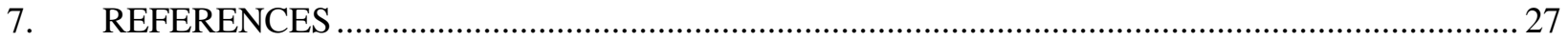




\section{FIGURES}

Figure 1. a) Layout of a Type 1A Basket. All units in inches. b) Bottom of first modified basket design showing "mouse hole" cutouts to promote cross circulation between cells. c) Bottom of second modified basket design showing "false bottom" and 0.25 " $(0.635 \mathrm{~cm})$

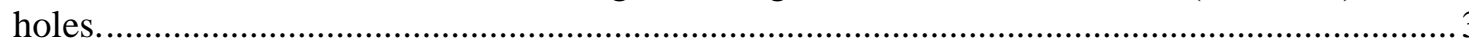

Figure 2. Cross-section of Surrogate Assembly Used in Modeling........................................................ 3

Figure 3. Cross- section view of cask/chamber with 1A basket showing numbering of fuel assemblies and location of siphon tube and vent.

Figure 4. a), b), and c) x-, y-, and z-components of velocity (respectively); bottom of assemblies (at 0.5 " [or $1.27 \mathrm{~cm}$ ] from basket floor), mousehole configuration, 50 volumes $/ \mathrm{hr}$.

Figure 5. a), b), and c) x-, y-, and z-components of velocity (respectively); middle of assemblies (at 25.25 " [or $64.135 \mathrm{~cm}$ ] from basket floor), mousehole configuration, 50 volumes $/ \mathrm{hr}$.

Figure 6. a), b), and c) x-, y-, and z-components of velocity (respectively); top of assemblies (at 48 " [or $121.92 \mathrm{~cm}$ ] from basket floor), mousehole configuration, 50 volumes $/ \mathrm{hr}$.

Figure 7. y-component of velocity of the a) mousehole and b) false bottom configurations; middle of assemblies (at 25.25" [or $64.135 \mathrm{~cm}$ ] from basket floor), mousehole configuration, 50 volumes/hr.

Figure 8. Temperature field in surrogate assemblies, mousehole configuration, a) after $14 \mathrm{hr}$ at 20 volumes/hr, and b) after $8 \mathrm{hr}$ at 50 volumes/hr.....

Figure 9. Comparison of surrogate temperatures in the a) mousehole and b) false bottom configurations.

Figure 10. Comparison of Assembly \#4 after $5 \mathrm{hr}$ with a) $0 \mathrm{~W}$, b) $10 \mathrm{~W}$, and c) $100 \mathrm{~W}$ heater (respectively).

Figure 11. Comparison of fluid domain cases after $5 \mathrm{hr}$ with a) a Fixed Temperature BC and b) Convective BC.

Figure 12. Comparison of fluid domain cases after $5 \mathrm{hr}$ a) with and b) without radiative heat transfer.

Figure 13. View of main chamber showing viewports.

Figure 14. Top view of upper chamber section showing 12 viewports each with a 2.75 " CF flange.

Figure 15. Mock ASNF design shown with a heating element to simulate decay heat. The coloring is attributable to meshing program. Drawing is to scale for gauge $13(0.072$ ” diameter) nichrome wire.

Figure 16. Sketch of mock ASNF assembly showing suggested locations of chemically treated plates with oxide layers. Note this is to scale assuming treated panels are 12 " in height/length.

Figure 17. Schematic of the test chamber showing connections and connection design 


\section{TABLES}

Table 1. Meshing Parameters...................................................................................................... 4

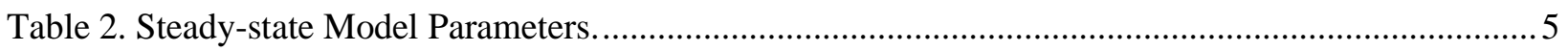

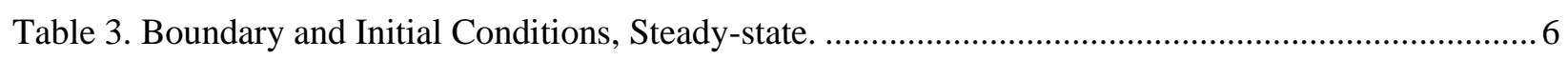

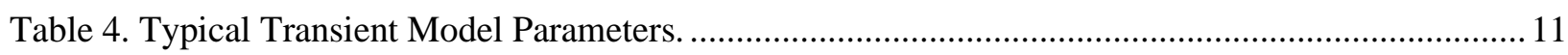

Table 5. Instruments to be used in data collection during drying tests shown with operating range

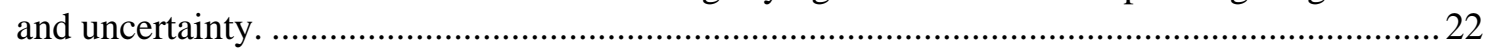

Table 6. Test cases proposed for forced helium drying evaluation.........................................................25

Table 7. Isolation holds in vacuum drying tests and criteria to proceed to next vacuum step...................25

Table 8. Test cases proposed for vacuum drying evaluation. ................................................................26 


\section{ACRONYMS}

$\begin{array}{ll}\text { ASNF } & \text { aluminum clad spent nuclear fuel } \\ \text { ATR } & \text { Advanced Test Reactor } \\ \text { BC } & \text { boundary condition } \\ \text { CF } & \text { conflat } \\ \text { FHD } & \text { Forced Helium Drying } \\ \text { FSO } & \text { full scale output } \\ \text { INL } & \text { Idaho National Laboratory } \\ \text { MOOSE } & \text { Multiphysics Object-Oriented Simulation Environment } \\ \text { NPT } & \text { national pipe thread } \\ \text { OES } & \text { optical emission spectroscopy } \\ \text { SEM } & \text { scanning electron microscopy } \\ \text { TC } & \text { thermocouple } \\ \text { TGA } & \text { thermogravimetric analysis } \\ \text { UFD } & \text { used fuel drying } \\ \text { XRD } & \text { x-ray diffraction }\end{array}$




\section{Aluminum-clad Spent Nuclear Fuel Engineering Scale Drying Experiment Design}

\section{EXPERIMENTAL CONDITIONS}

The objective of this research is to assess the fundamental effectiveness of the two widely accepted processes for drying spent nuclear fuel for application with oxide corrosion layers on aluminum alloy (Smith, 2019). Forced helium drying (FHD) in normal operation is expected to achieve assembly temperatures not to exceed $250^{\circ} \mathrm{C}$ with a pressure during recirculation between 4 and $5 \mathrm{~atm}$. Gas flow rates are sought to achieve 50 volume exchanges of the chamber per hour. Vacuum drying operations are expected to achieve and maintain pressures below 3 Torr for greater than 30 minutes. The Engineering Scale Design is intended to have additional capability and margin to test at conditions exceeding $250^{\circ} \mathrm{C}$ to provide additional data for later modeling efforts.

\section{CFD SIMULATIONS AND EXPERIMENTAL OPERATION}

The problem domain was adapted from work performed by INL to study fuel performance in longterm storage in one full canister. The solid part of this domain consists of a single, modified Type 1A Basket and 10 aluminum surrogate assemblies. The fluid part consists of helium gas filling the remaining volume, including each of the ten slots in the basket, the gaps between the surrogate plates, and an $\sim 5$ " $(12.7 \mathrm{~cm})$ gap from the top of the basket to the ceiling chamber.

A Type 1A Basket consists of a rectangular grid formed by $3 / 8 "(0.9525 \mathrm{~cm})$ thick stainless-steel plates (Snow, 2007), as seen in Figure 1a. Each basket is 51" $(129.54 \mathrm{~cm})$ tall and can contain a maximum of ten assemblies. Two different configurations of the Type 1A Basket have been considered during the initial modeling phase. In the first, a series of "mouse holes" have been cut at the base of the basket walls (Figure 1b) to promote flow between each slot. Each arc is parabolic, with a width and height equal to one half of the total wall length. The second configuration includes a $2.5 "(6.35 \mathrm{~cm})$ tall "false bottom," with an array of nine 0.25 " $(0.635 \mathrm{~cm})$ holes drilled in the floor of the basket, as pictured in Figure 1c. The total fluid volume of the "mousehole" configuration is $\sim 10,200 \mathrm{in}^{3}(167.15 \mathrm{~L})$, and the fluid volume of the "false bottom" configuration is $\sim 10,800 \mathrm{in}^{3}(177.0 \mathrm{~L})$.

Each surrogate assembly is made from a series of twenty $3.15 " \mathrm{x} 0.05 " \mathrm{x} 49.5$ " $(8.001 \mathrm{~cm} \times 0.127 \mathrm{~cm}$ $\mathrm{x} 125.73 \mathrm{~cm})$ plates and nineteen pairs of 0.5 " x "0.081" x 49.5” (1.27 cm x $0.2057 \mathrm{~cm} \mathrm{x} 125.73 \mathrm{~cm})$ spacers. An example of such a cross-section is shown in Figure 2. The dimensioning was chosen to yield a surface area and metal volume as close to that of the true ATR assemblies as possible; the stated dimensions thus yield a surface area of $43.31 \mathrm{ft}^{2}$ (vs. $43.32 \mathrm{ft}^{2}\left[40,246 \mathrm{~cm}^{2}\right]$ for ATR fuel) and volume of $234.6 \mathrm{in}^{3}[3.844 \mathrm{~L}]$ (vs. $\sim 170 \mathrm{in}^{3}[2.7858 \mathrm{~L}]$ for ATR fuel, a $38 \%$ increase).

In addition, plates \#1, 7,13, and 20 are extended an extra half inch $(1.27 \mathrm{~cm})$ in length in order to lift the assemblies off the floor of the basket and allow circulation under and through the surrogate. For modeling purposes, the plates and spacers are merged together before being imported into the model.

Under forced recirculation conditions, hot helium gas is blown into the chamber through a 3/4" siphon tube entering the chamber through the roof. In the "mousehole" configuration, the siphon tube terminates $1 / 10$ " $(0.254 \mathrm{~cm})$ from the basket floor and blows directly into the basket. Under the "false bottom" configuration, the siphon tube instead blows into the void space beneath the basket and is drawn upwards through the holes drilled in the basket floor. Flow through and heat transfer from the siphon tube is omitted in all simulations. In each configuration, helium exits the chamber through a vent in the roof of the chamber, directly across from the siphon tube. The layout of the chamber, including all basket 
walls, assemblies, and the siphon tube and can be seen in Figure 3. Under vacuum conditions, gases can be pulled either through the vent or the siphon tube.

a)

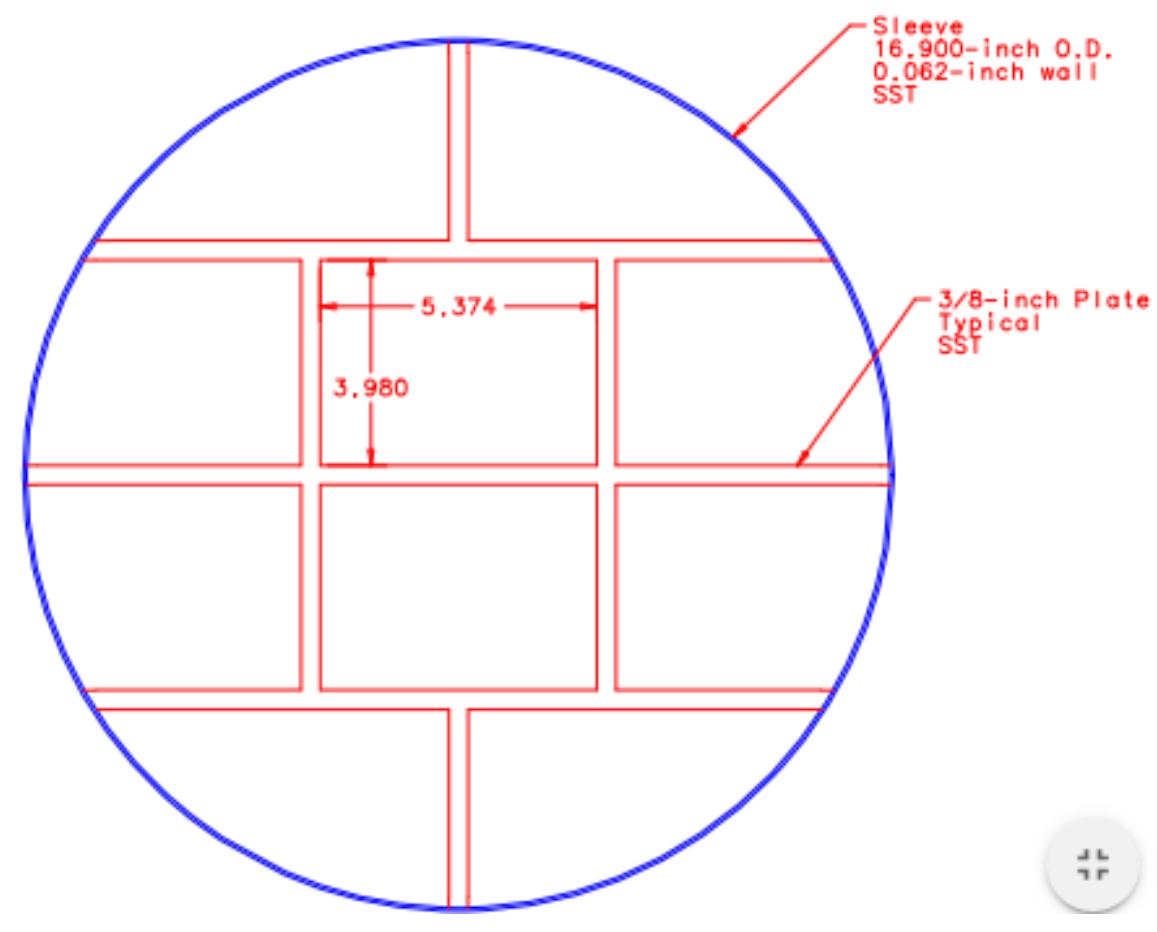

b)

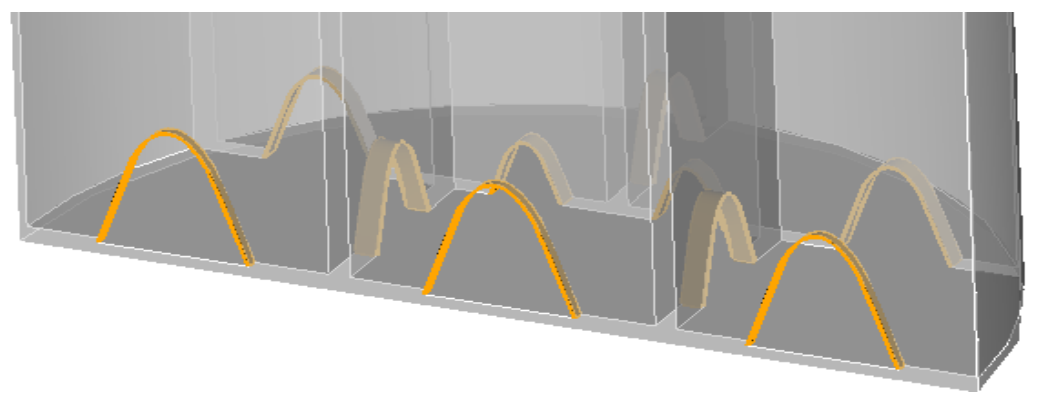

c)

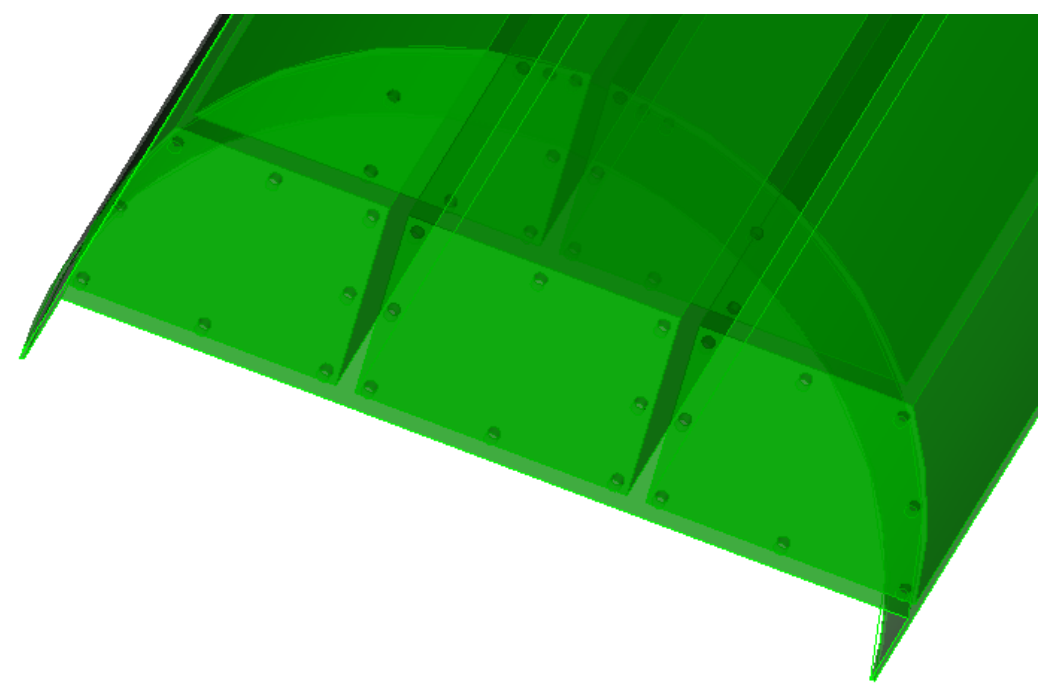


Figure 1. a) Layout of a Type 1A Basket. All units in inches. b) Bottom of first modified basket design showing "mouse hole" cutouts to promote cross circulation between cells. c) Bottom of second modified basket design showing "false bottom" and 0.25 " $(0.635 \mathrm{~cm})$ holes.

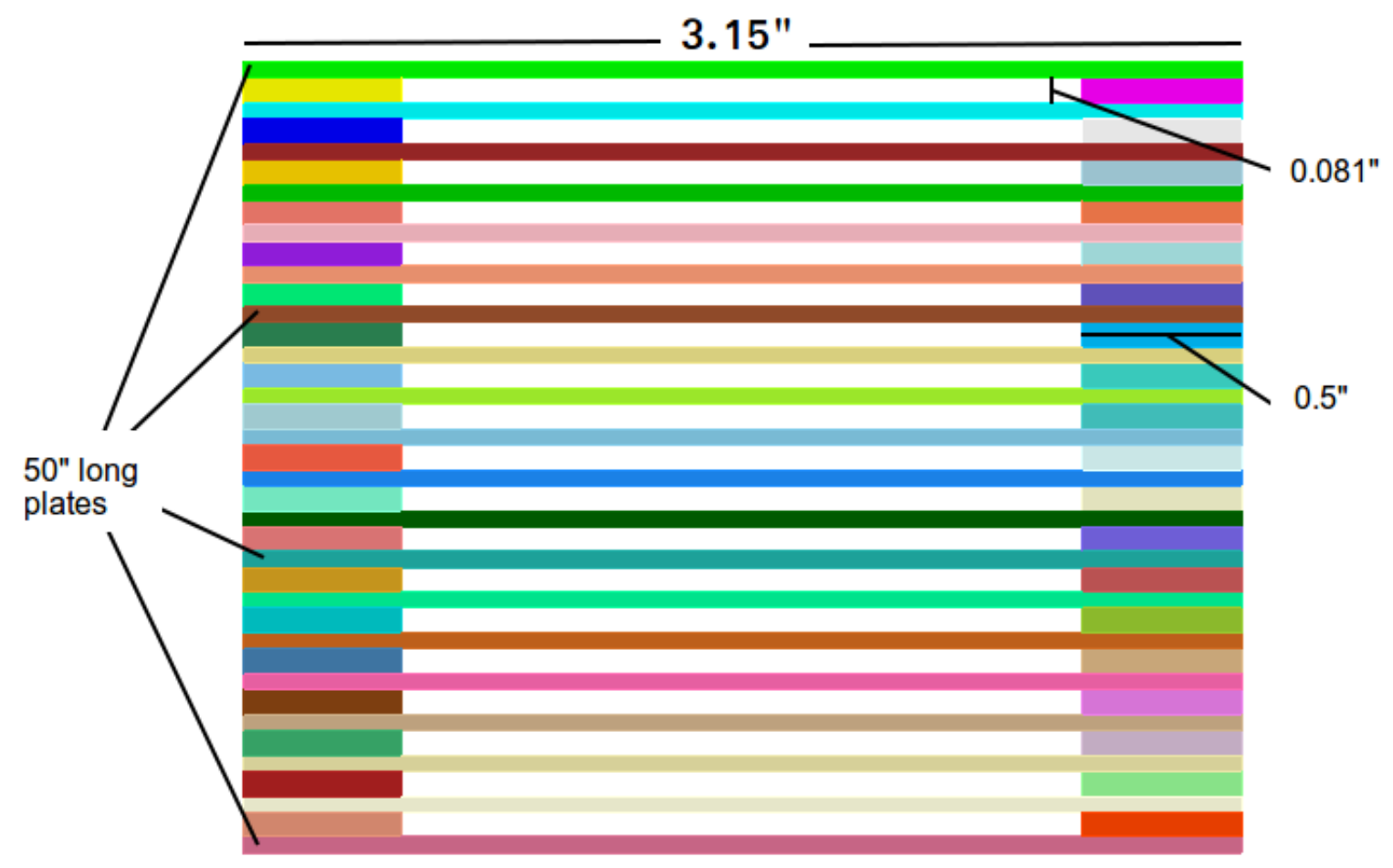

Figure 2. Cross-section of Surrogate Assembly Used in Modeling. 


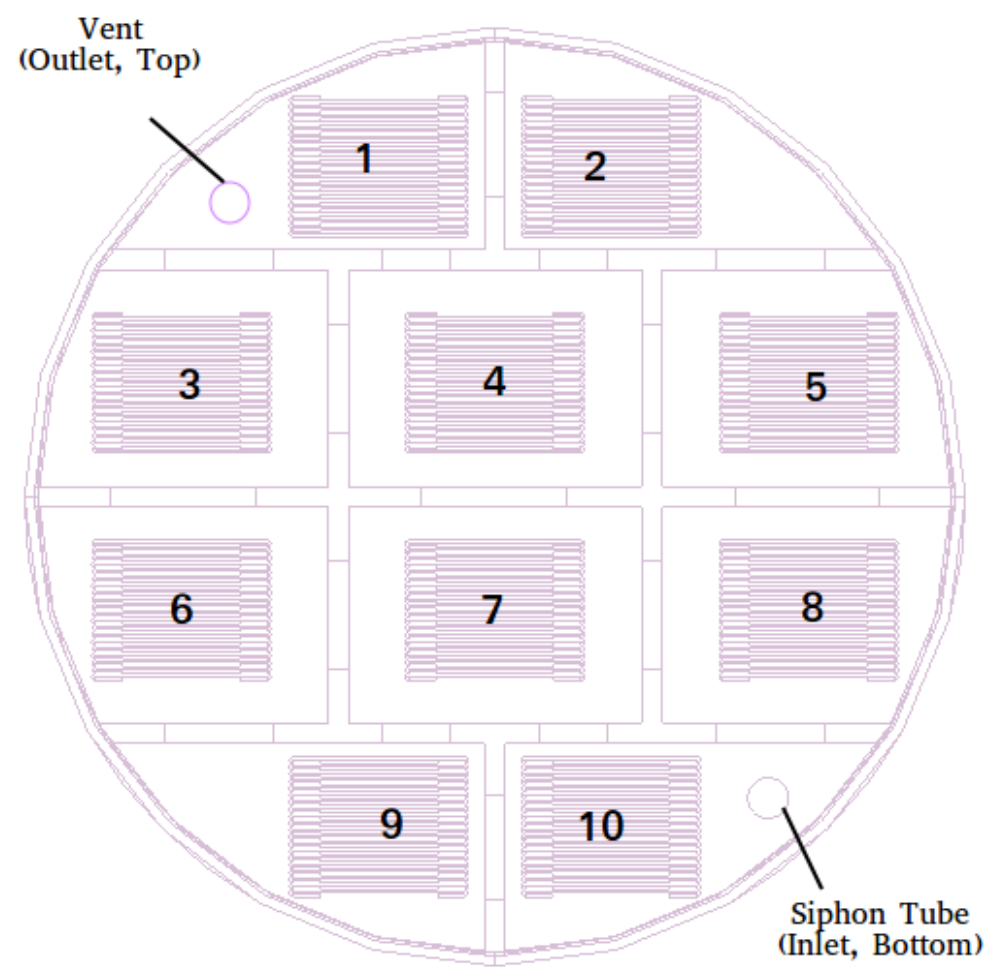

Figure 3. Cross- section view of cask/chamber with 1A basket showing numbering of fuel assemblies and location of siphon tube and vent.

All geometries and volumes were created using Trellis 16.3.4, and saved in the *.step format for compatibility purposes. The geometries were then imported into STAR-CCM+13.02.013 and meshed using the program's native Automated Mesh feature. All features were left with their default values except for those listed in Table 1 which were chosen based on the parameters used in INL's previous work (Abboud, 2018a; Abboud 2018b). The resulting mesh consisted of about 3.1 million cells in the fluid and solid regions.

Table 1. Meshing Parameters.

\begin{tabular}{|c|c|}
\hline \multirow{4}{*}{ Meshers } & Surface Remesher \\
\cline { 2 - 2 } & Automatic Surface Repair \\
\cline { 2 - 2 } & Polyhedral Mesher \\
\cline { 2 - 2 } Controls & Thin Mesher \\
\hline \multirow{2}{*}{} & Base Size $-0.05 \mathrm{~m}$ \\
\cline { 2 - 2 } & Target Surface Size, $\%$ of Base -10.0 \\
\cline { 2 - 2 } & Minimum Surface Size, $\%$ of Base -10.0 \\
\hline
\end{tabular}

Before attempting any transient modeling, it is common to first establish the flow field via a steadystate model. Once the flow field is obtained, the solution is frozen, the energy equations are activated, and a transient solution can be found. This is done in the interest of efficiency. By freezing the continuity and momentum equations, the number of equations that need to be solved on each time step is reduced from five to one (the energy equation). The demand for computational resources is thereby also reduced. 
The models selected for all steady-state simulations are tabulated in Table 2 below. The applied boundary and initial conditions are listed in Table 3. In the initial effort, two different flow rates were considered, $11.8568 \mathrm{~m} / \mathrm{s}$ (or 20 volumes $/ \mathrm{hr}$ ) and $29.642 \mathrm{~m} / \mathrm{s}$ (or 50 volumes $/ \mathrm{hr}$ ), in an effort to reach an appropriate recommendation. In each case, the simulation was given 2000 iterations to achieve an acceptable solution.

In general, the only difference between flow rates was in the magnitude of the velocities, with the higher flow rate of 50 volumes/hr unsurprisingly yielding higher velocities. Results for this flow rate are pictured below in Figures 4, 5, and 6 Upon closer inspection, it becomes clear that there is little to no flow occurring in the gaps between fuel plates. This implies that the main mechanism for heating the interior of the assemblies comes from conduction.

In addition, the flow is highly asymmetric. The tendency is for the gases to be drawn upwards and over the majority of the assemblies through the plenum region at the top of the chamber. As a result, assembly \#10 and its neighbors see the majority of the flow in the axial direction, while the rest see very little.

The conditions in Tables 2 and 3 were then reapplied to a basket with a "false bottom" configuration. The findings were the same, with the exception of a notable increase in the amount of symmetry found in the solution. An illustrative example of this is seen in Figure 7, depicting the y-component of velocity at the midpoint of the assemblies. The end result of this is a much more even heating of the assemblies, with the energy from the hot gases being distributed amongst the surrogates.

Table 2. Steady-state Model Parameters.

\begin{tabular}{|c|c|}
\hline \multicolumn{2}{|c|}{ Solid Domain (Aluminum Surrogates and Steel Basket) } \\
\hline Basket Configuration & Mousehole \\
\hline Solver & Steady \\
\hline Medium & Solid \\
\hline Equation of State & Constant Density \\
\hline \multicolumn{2}{|c|}{ Fluid Domain (Helium) } \\
\hline Solver & Steady \\
\hline Medium & Gas \\
\hline Continuity/Momentum & Segregated Flow \\
\hline \multirow{2}{*}{ Turbulent Viscous Regime } & Keynolds-Averaged Navier Stokes Equations \\
\cline { 2 - 2 } & Exact Wall Distance \\
\hline Equation of State & Ideal Gas \\
\hline
\end{tabular}


Table 3. Boundary and Initial Conditions, Steady-state.

\begin{tabular}{|c|c|}
\hline \multicolumn{2}{|c|}{ Initial Conditions } \\
\hline Pressure & $4 \mathrm{~atm}$ \\
\hline Temperature & $300 \mathrm{~K}$ \\
\hline Velocity & {$[0,0,0] \mathrm{m} / \mathrm{s}$} \\
\hline \multicolumn{2}{|c|}{ Boundary Conditions } \\
\hline Boundary & Flow Rate \\
\hline \multirow{2}{*}{ Siphon Tube Inlet } & $11.8568 \mathrm{~m} / \mathrm{s}(20$ volumes $/ \mathrm{hr})$ \\
\hline \multirow{2}{*}{ Outlet Vent (at roof of chamber) } & $29.642 \mathrm{~m} / \mathrm{s}(50$ volumes $/ \mathrm{hr})$ \\
\cline { 2 - 2 } & $11.8568 \mathrm{~m} / \mathrm{s}(20$ volumes $/ \mathrm{hr})$ \\
\hline
\end{tabular}




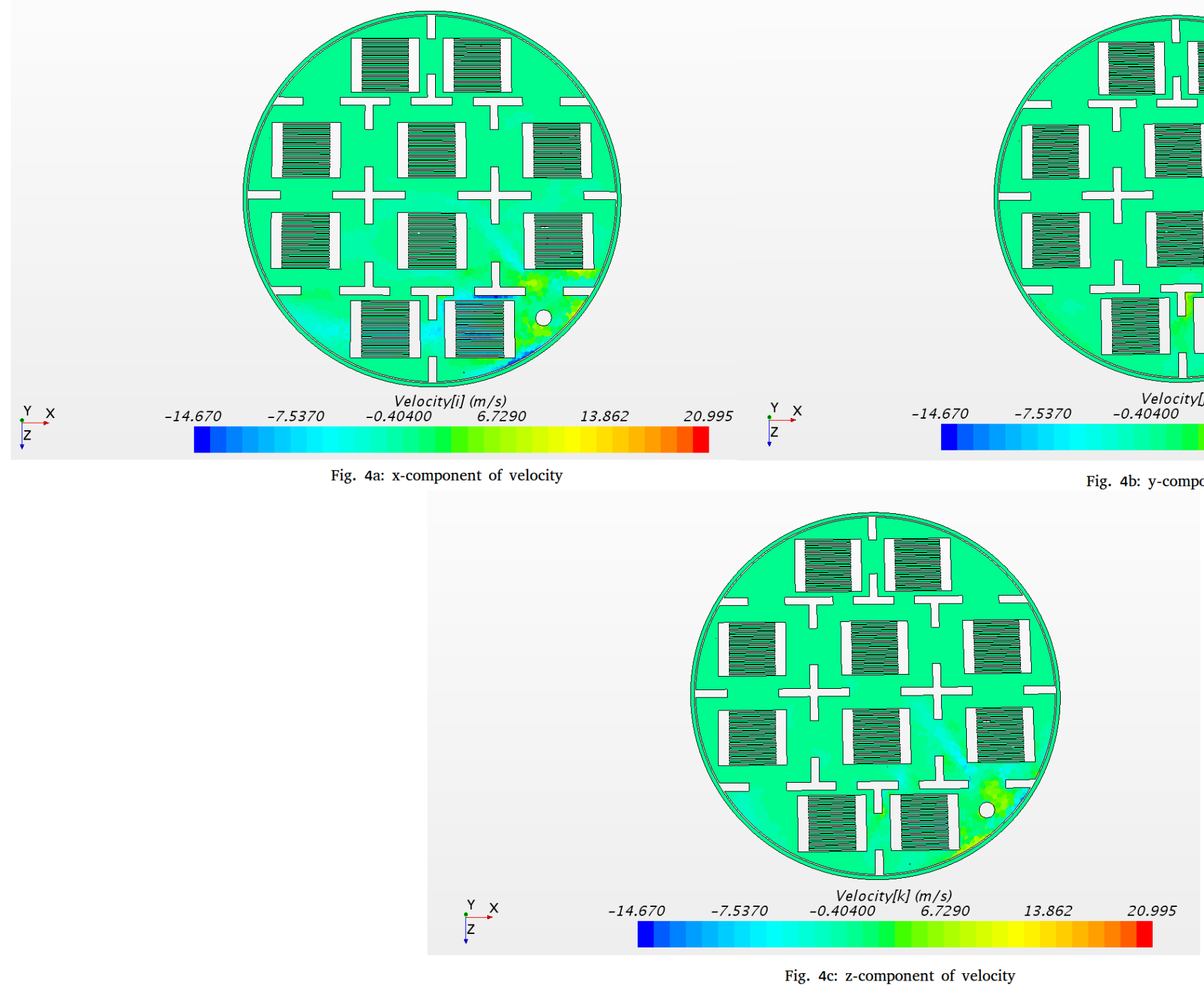

Figure 4. a), b), and c) x-, y-, and z-components of velocity (respectively); bottom of assemblies (at 0.5 " [or $1.27 \mathrm{~cm}$ ] from basket floor), mousehole configuration, 50 volumes/hr. 


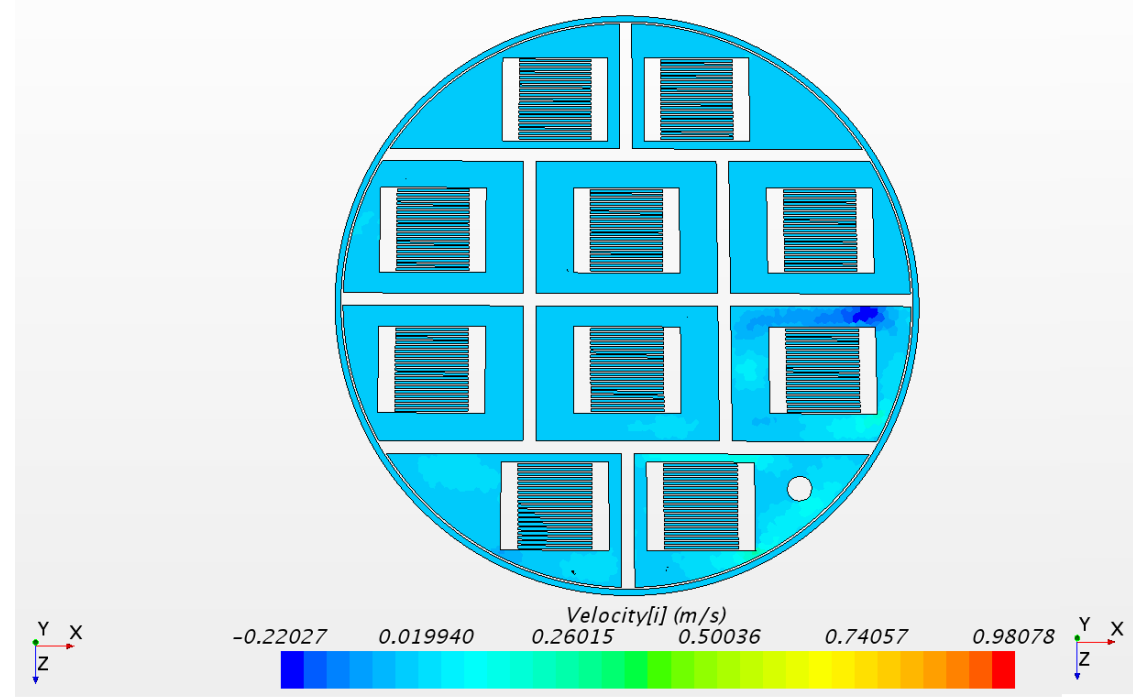

Fig. 5a: x-component of velocity

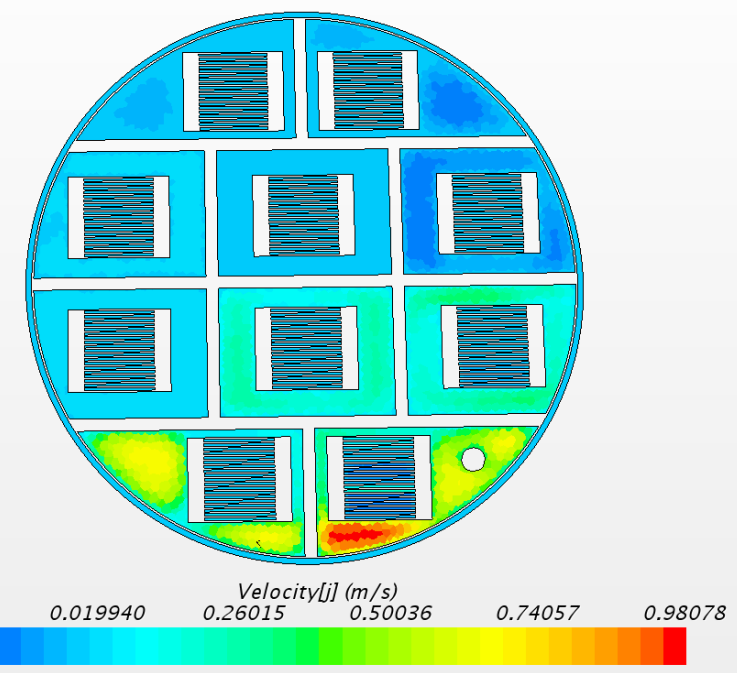

Fig. 5b: y-component of velocity

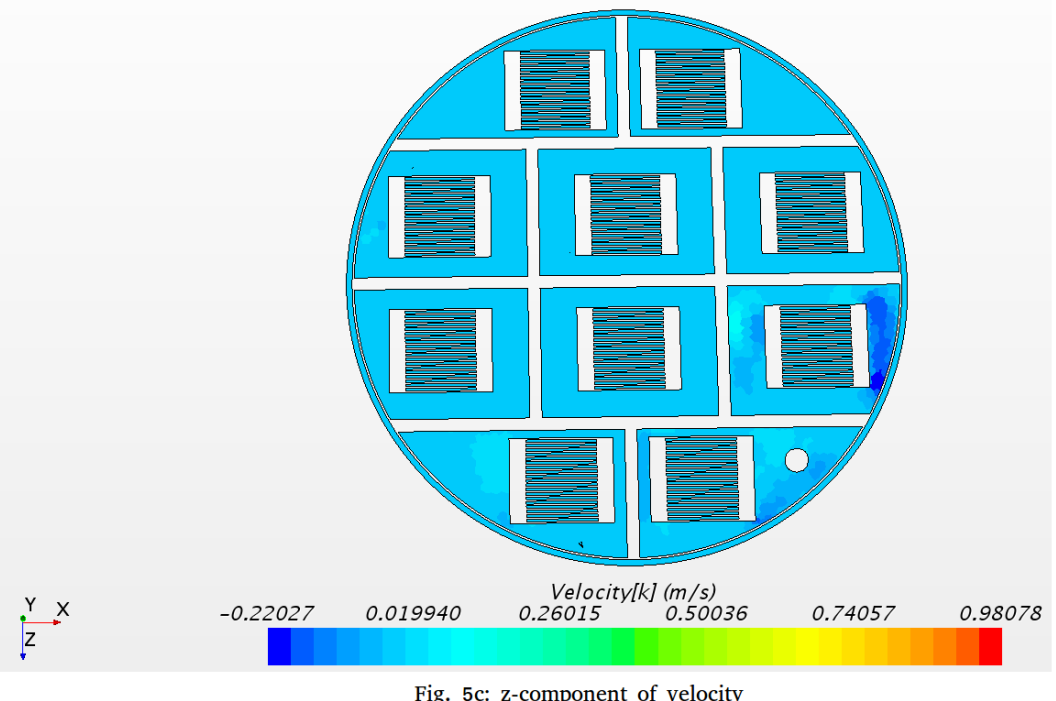

Figure 5. a), b), and c) x-, y-, and z-components of velocity (respectively); middle of assemblies (at 25.25" [or $64.135 \mathrm{~cm}$ ] from basket floor), mousehole configuration, 50 volumes/hr. 


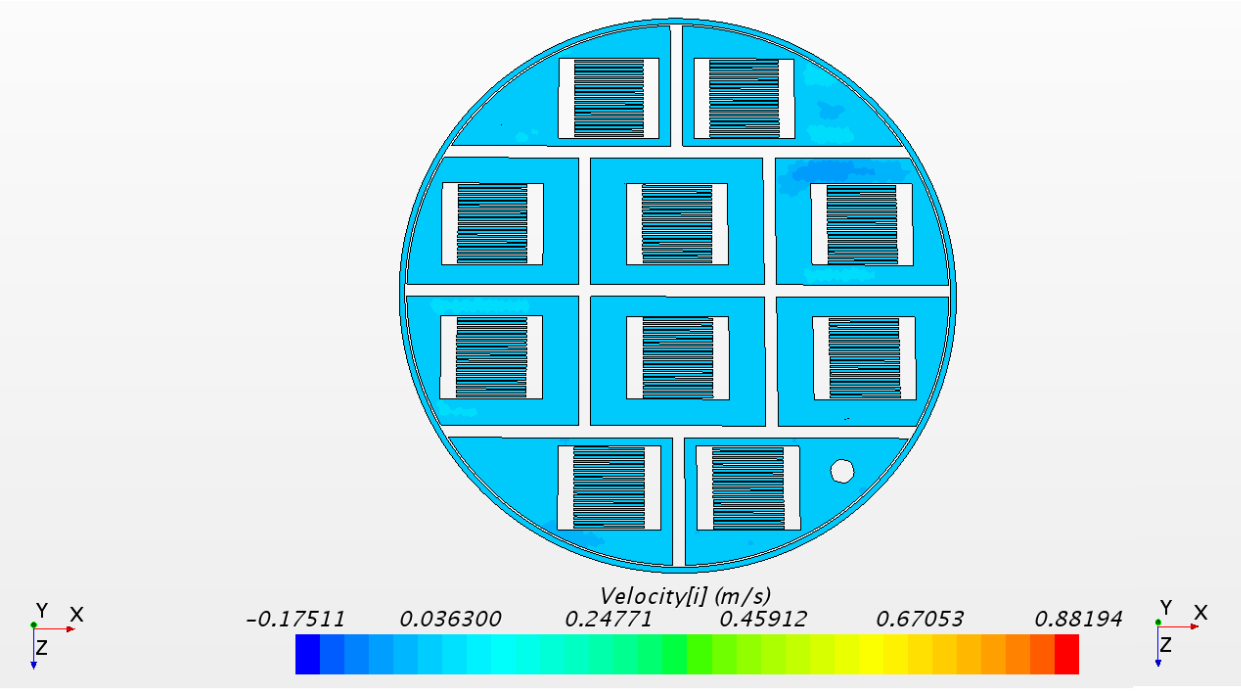

Fig. 6a: x-component of velocity

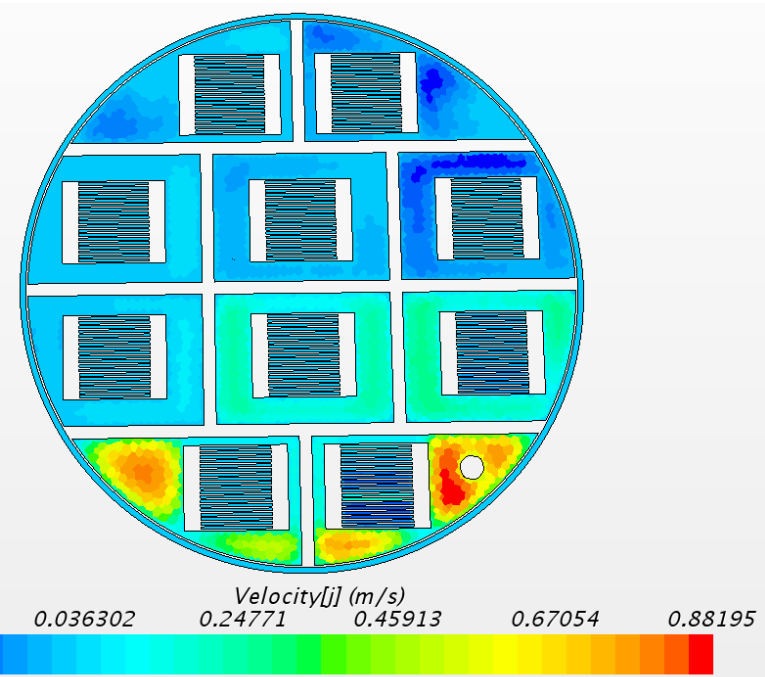

Fig. 6b: y-component of velocity

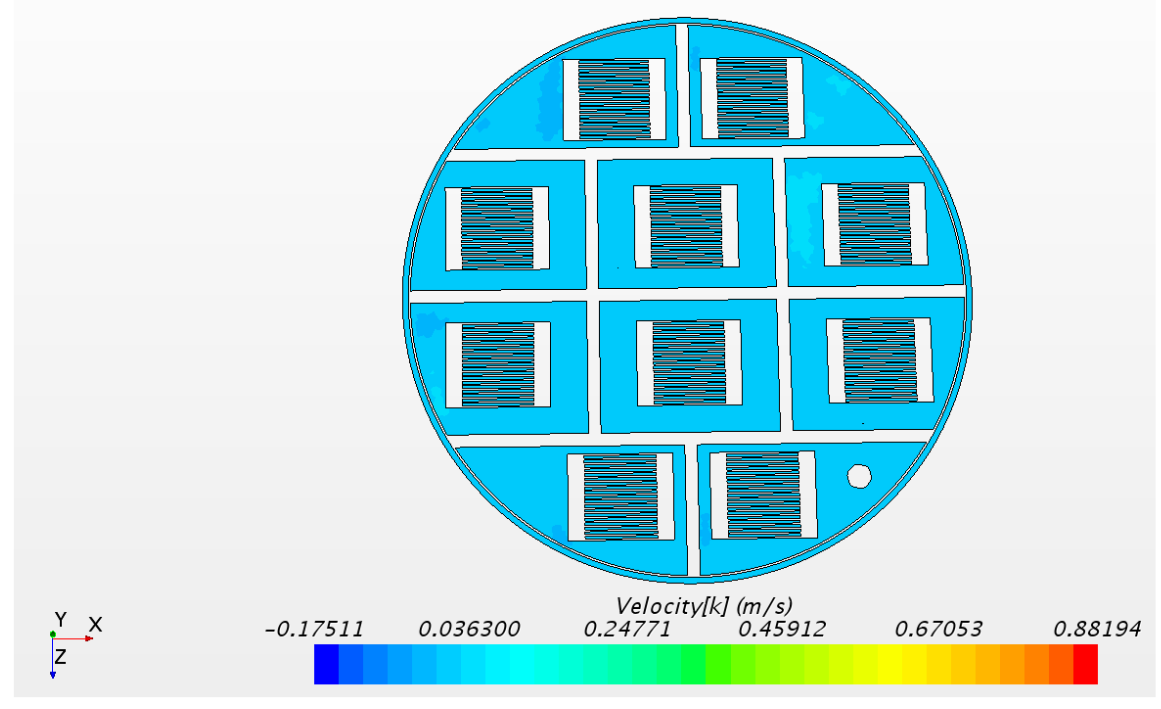

Fig. 6c: z-component of velocit

Figure 6. a), b), and c) x-, y-, and z-components of velocity (respectively); top of assemblies (at 48" [or $121.92 \mathrm{~cm}$ ] from basket floor), mousehole configuration, 50 volumes/hr. 
a)

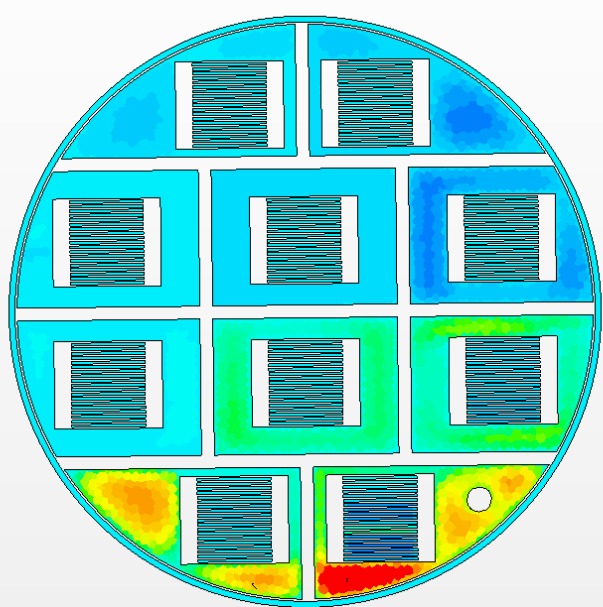

$\underset{\mathrm{Z}}{\stackrel{Y}{\longrightarrow}}$

$-0.021358$

$\begin{array}{ll}\text { Velocity[j] } & (\mathrm{m} / \mathrm{s}) \\ 0.17755 & 0.3764\end{array}$

0.57538

$0.77429 \underset{Z}{\mathrm{Y} X}$

b)

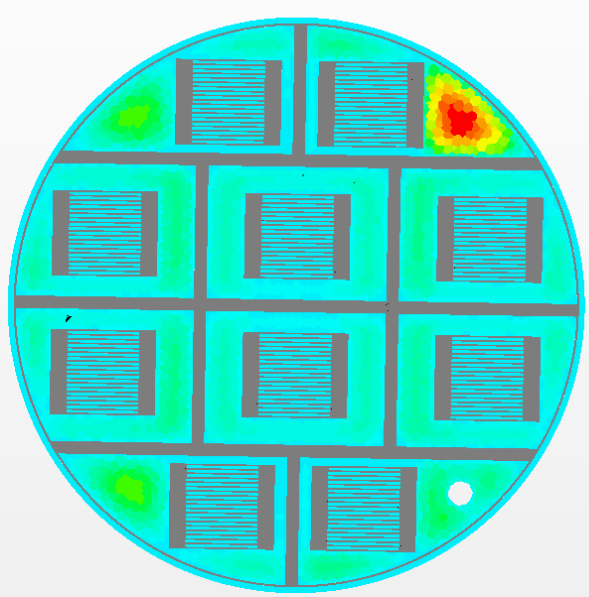

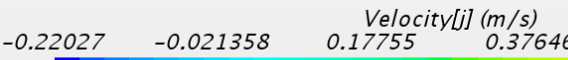

0.57538

0.77429

Figure 7. y-component of velocity of the a) mousehole and b) false bottom configurations; middle of assemblies (at 25.25 " [or $64.135 \mathrm{~cm}$ ] from basket floor), mousehole configuration, 50 volumes $/ \mathrm{hr}$. 
Once the flow field was established, the steady-state solution was used as a seed for the transient solution. The Steady solver was replaced by the Implicit Unsteady solver, the energy equations were activated (Segregated Solid Energy for the surrogates/basket and Segregated Fluid Temperature for the helium), and additional boundary conditions were applied. A summary of these changes can be found in Table 4.

Table 4. Typical Transient Model Parameters.

\begin{tabular}{|c|c|c|}
\hline \multicolumn{3}{|c|}{ Transient Solver Information } \\
\hline Type & \multicolumn{2}{|c|}{ Implicit Unsteady } \\
\hline Time Step Length & \multicolumn{2}{|c|}{$10 \mathrm{~s}$} \\
\hline Iterations per Step & \multicolumn{2}{|c|}{5} \\
\hline \multirow{2}{*}{ Physical Time } & \multicolumn{2}{|c|}{$14 \mathrm{hr}$ (20 volumes/hr) } \\
\hline & \multicolumn{2}{|c|}{$8 \mathrm{hr}$ (50 volumes/hr) } \\
\hline \multicolumn{3}{|c|}{ Boundary Conditions } \\
\hline Boundary & Condition & Value \\
\hline Siphon Tube Inlet & Static Temperature & $523 \mathrm{~K}\left(250^{\circ} \mathrm{C}\right)$ \\
\hline \multirow{2}{*}{ Walls } & \multirow{2}{*}{ Convection } & $\mathrm{h}=10 \mathrm{~W} / \mathrm{m}^{2}-\mathrm{K}$ \\
\hline & & $\mathrm{T}_{\infty}=300 \mathrm{~K}$ \\
\hline
\end{tabular}

Figure 8 illustrate the difference in the temperature fields of the gas, assemblies, and basket after 14 hours (at 20 volumes/hr) and 8 hours (at 50 volumes/hr), respectively, using the mousehole configuration. The most obvious result is the dramatic improvement in performance of the system at the higher flow rate. Despite being under recirculation for significantly less time, the final condition was comparable or better. It is therefore recommended that the floor for the experimental flow rate be established at 50 volumes $/ \mathrm{hr}$ at a chamber pressure of $4 \mathrm{~atm}$.

It is also clear that some of the assemblies warm much more slowly than others due to uneven flow noted in the previous section. This is most pronounced in assemblies \#1 and \#3 (as numbered in Figure 4) but can also be seen in assemblies \#2 and \#6 at earlier times.

Figure 9 is a comparison between the temperatures found in the assemblies in both the "mousehole" and "false bottom" configurations. The flow rate in each case is 50 volumes $/ \mathrm{hr}$, and the figure depicts the temperatures at $\mathrm{t}=5 \mathrm{hrs}$. The most obvious difference is in the distribution between assemblies. The highly symmetric flow characteristic of the "false bottom" type leads to a consistent bottom-to-top gradient with temperatures between $\sim 315 \mathrm{~K}$ and $395 \mathrm{~K}$ in all assemblies. On the other hand, the gradients under the "mousehole" design vary greatly with a given assembly's distance from the siphon tube; a maximum temperature of $\sim 500 \mathrm{~K}$ is observed at the bottom of assembly \#10, directly adjacent to the inlet, while assemblies \#1 and \#2, the two furthest away, have temperatures ranging from $320 \mathrm{~K}$ to $355 \mathrm{~K}$. Therefore, to provide a more even and thorough heating, the "false bottom" configuration is preferred. 
a)

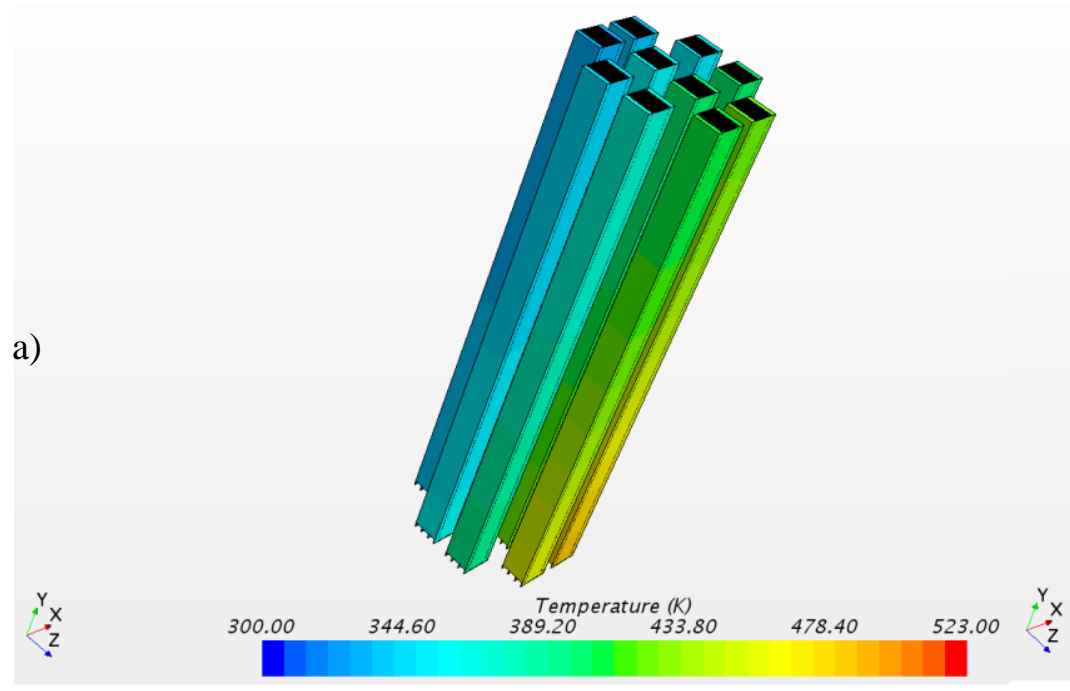

b)

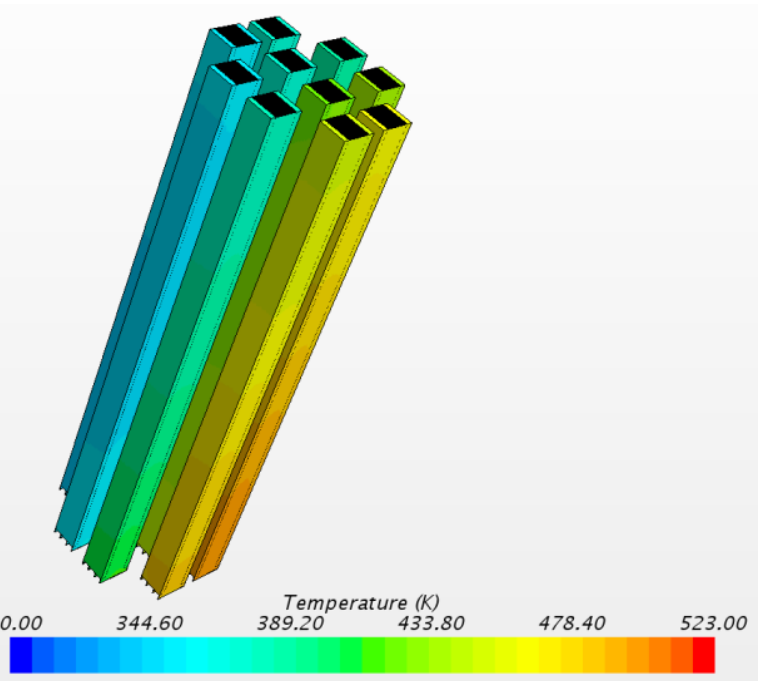

Figure 8 . Temperature field in surrogate assemblies, mousehole configuration, a) after $14 \mathrm{hr}$ at 20 volumes/hr, and b) after $8 \mathrm{hr}$ at $50 \mathrm{volumes} / \mathrm{hr}$.

a)

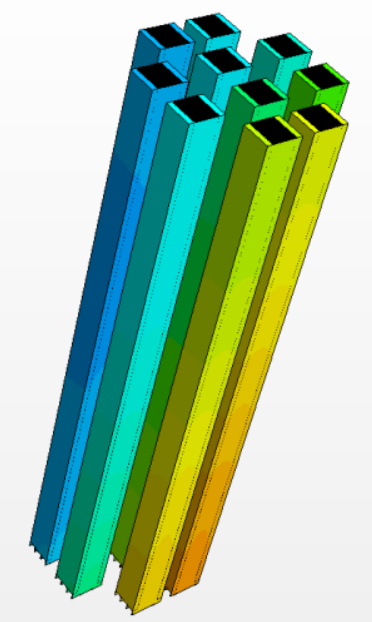

b)

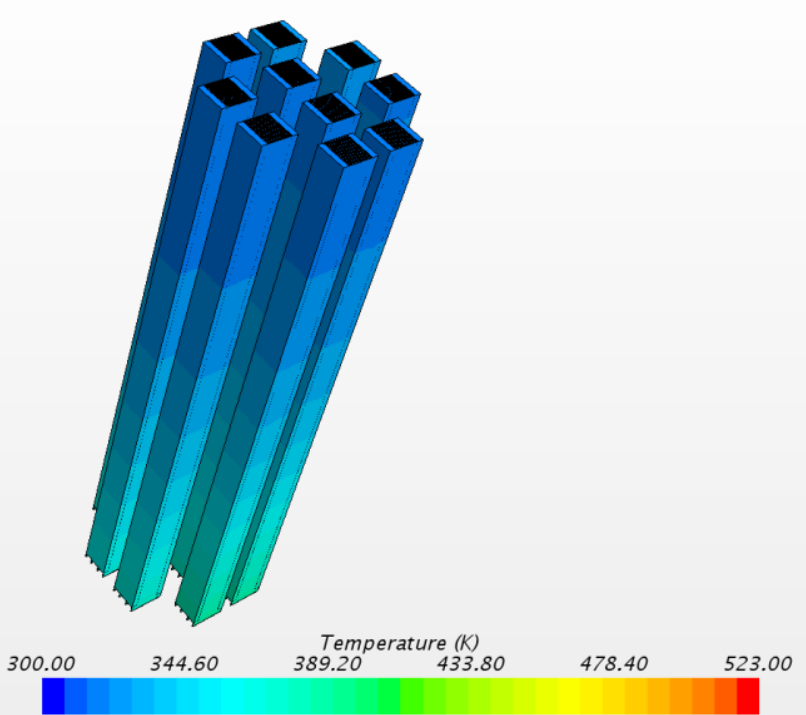

Figure 9. Comparison of surrogate temperatures in the a) mousehole and b) false bottom configurations. 
In addition to the basic characterization work described above, three other special cases were studied, each under the "mousetrap" configuration. In the first case, the effect of adding a nichrome wire heater insulated in boron nitride for simulating decay heat to a single assembly was considered. The domain was re-meshed to include the heater in assembly \#4 and the flow field was established as described above. Two transient simulations were then run and compared with the baseline, non-heated case: one with the heater producing $10 \mathrm{~W}$ of power, and one producing $100 \mathrm{~W}$ of power. Figure 10 illustrates the temperature field in assembly \#4 after five hours.

In absolute terms, very little difference was observed between the minimum and maximum temperatures of the $0 \mathrm{~W}$ and $10 \mathrm{~W}$ cases, although the low power case does appear to have warmed slightly more evenly. In both cases, the assembly is first warmed primarily through conduction after the hot gas transfers the bulk of its heat at the top and bottom. On the other hand, the $100 \mathrm{~W}$ case is both fifteen degrees Kelvin warmer and heats in a more uniform manner.

The second special case studied the impact of a fixed temperature boundary condition replacing the convective boundary condition on the walls. For this simulation, a new boundary condition was written with the following definition:

$$
\begin{gathered}
T \leq 95 C, T=T \\
T>95 C, T=95 C
\end{gathered}
$$

This allows the chamber walls to heat to a temperature of $363 \mathrm{~K}$ before becoming fixed. Results in the fluid domain after five hours are shown in Figure 11.

Finally, in one case, the STAR-CCM+ model for radiative heat transfer was activated, simulating grey-bodied (emissivity $=0.8$ ) surface-to-surface radiation. A comparison between the results with and without radiation can be seen in Figure 12. Ultimately, it was concluded that radiative heat transfer has a negligible effect on the solution, and given the computational expense involved its use is not recommended in future simulations. 


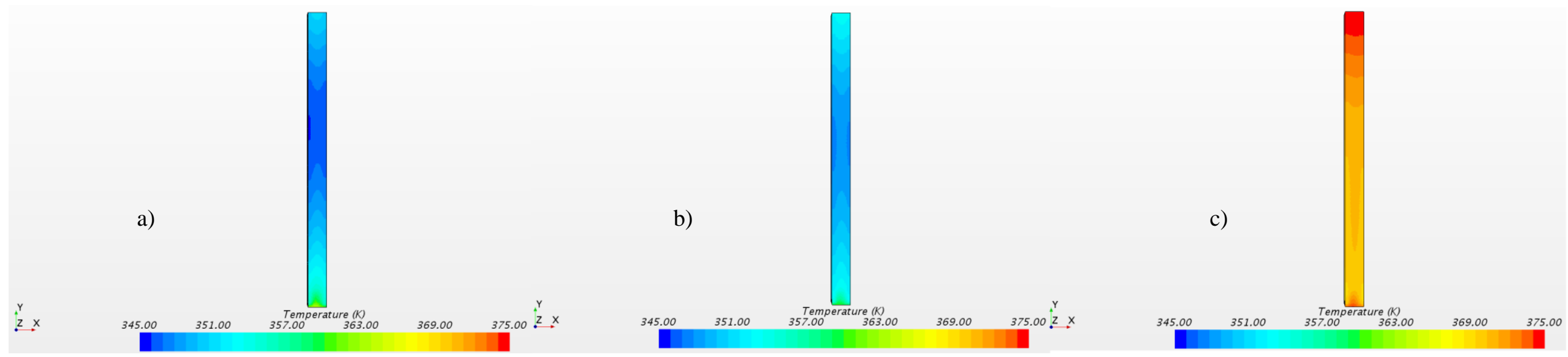

Figure 10. Comparison of Assembly \#4 after $5 \mathrm{hr}$ with a) $0 \mathrm{~W}$, b) $10 \mathrm{~W}$, and c) $100 \mathrm{~W}$ heater (respectively).
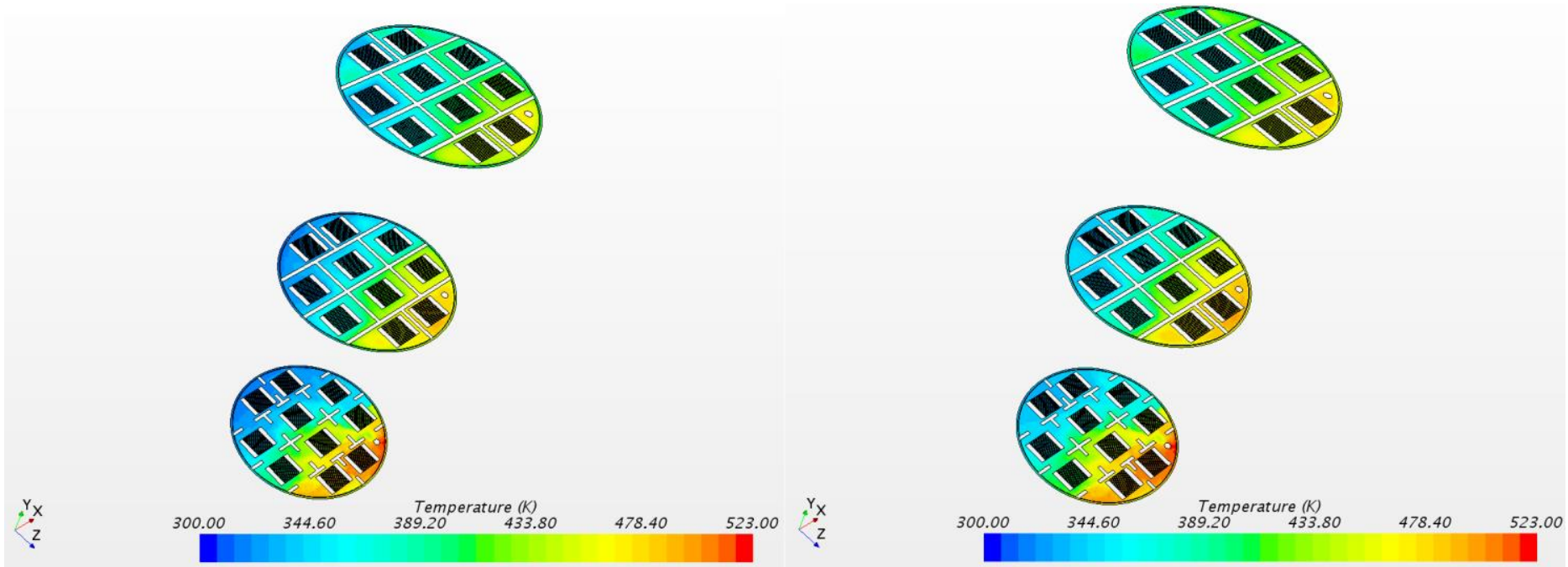

Figure 11. Comparison of fluid domain cases after $5 \mathrm{hr}$ with a) a Fixed Temperature BC and b) Convective BC. 


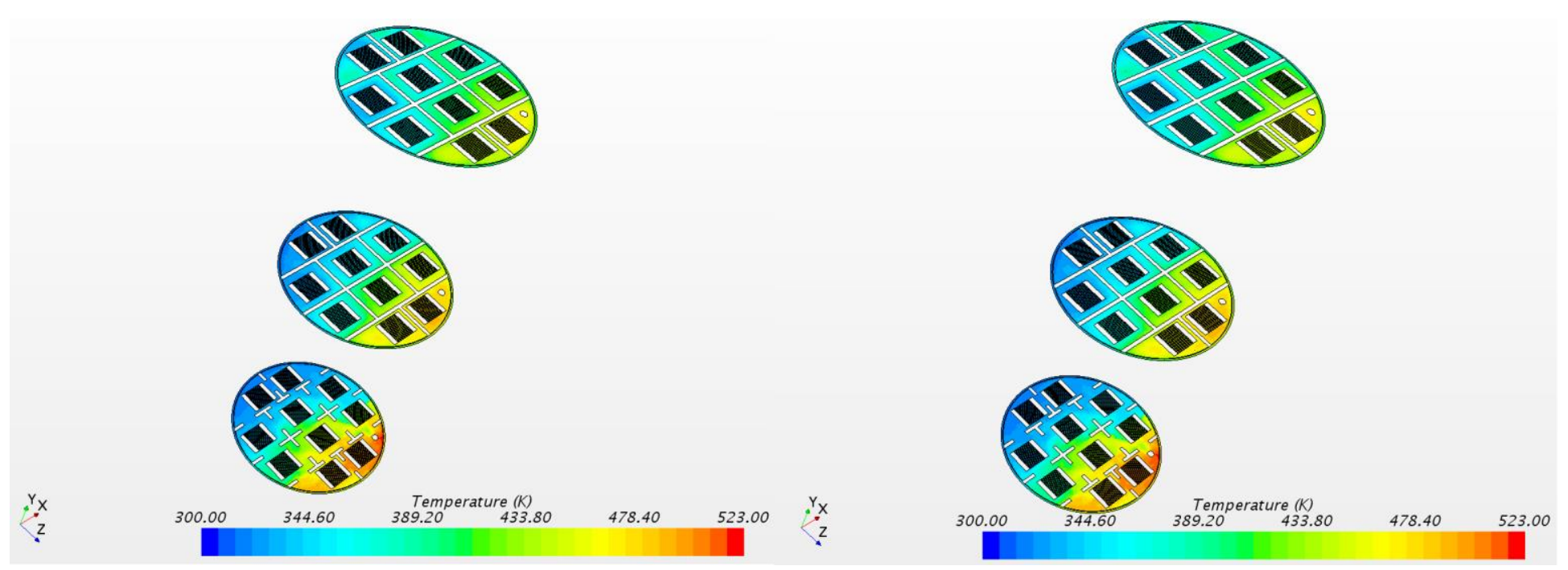

Figure 12. Comparison of fluid domain cases after $5 \mathrm{hr}$ a) with and b) without radiative heat transfer.

\section{EQUIPMENT \\ 3.1 Drying Chamber}

The drying chamber is designed to accommodate a single layer of ASNF assemblies and to be of the same 18 " $(45.72 \mathrm{~cm})$ external diameter (internal diameter 17.25 " or $43.82 \mathrm{~cm}$ ) to accommodate the Type 1A Basket. It will be fabricated in two sections joined by a bolted flange. The lower/main section will be 52 " $(132.08 \mathrm{~cm})$ in height such that the top sits approximately $1 "(2.53 \mathrm{~cm})$ above the top of the basket and assemblies. For the basket design with a "false bottom", the top of the lower/main section would sit approximately 1.5 " $(3.81 \mathrm{~cm})$ below the top of the basket. The upper section will be 12 " $(30.48 \mathrm{~cm})$ in height to contain the ports for power, instrumentation, and gas exchange. A smaller height for this upper section is tolerable but 12 " $(30.48 \mathrm{~cm})$ was selected to ensure proper clearance of the bolts for the chamber flange and the ports on the upper flange which necessarily protrude from the chamber wall. With an external diameter of 18 " $(45.72 \mathrm{~cm})$ this is not a standard conflat designed flange and so the bolted design will follow the Holtec experience with bolted flanges for storage canisters. The total internal volume of the combined chamber (empty) and less any additional volume owing to joints with added ports is approximately $15,000 \mathrm{in}^{3}(245.8 \mathrm{~L})$. In addition to the thermocouples placed outside the chamber, insulation (R30 or greater) will be added to the outside to reduce heat losses. Four strands of heating tape will be used to maintain a nearly constant chamber wall temperature of $75^{\circ} \mathrm{C}$. The reference model is Briskheat, (SDCJFA-BWH051080L) with SDC temperature controller each $8 \mathrm{ft}(2.4 \mathrm{~m})$ in length and capable of 627 watts.

\subsection{Ports/Flanges}

For the main chamber section, four viewports will be added with a 10" diameter CF flange (see Figure 13). These flanges will contain a centered zero length adapter to reduce to 2.75 " CF. Zinc selenide viewports $(2.75$ " CF) attached to the 10 " flanges will permit viewing with a thermal camera during operation. Quartz viewports $(2.75$ " $\mathrm{CF})$ will be available for interchange when optical viewing is desired. Two viewports are located on one side of the chamber aligned with Assembly 10 and the siphon tube. These are located at the midplane and near the bottom. The other two are located on the opposite side aligned with Assembly 1 and the vent. These are located at the midplane and near the top of chamber main section. A cutout of the basket is required at these locations to permit direct viewing into the cell containing the ASNF assembly and siphon tube (in Cell \#10) and ASNF assembly (in Cell \#1). 


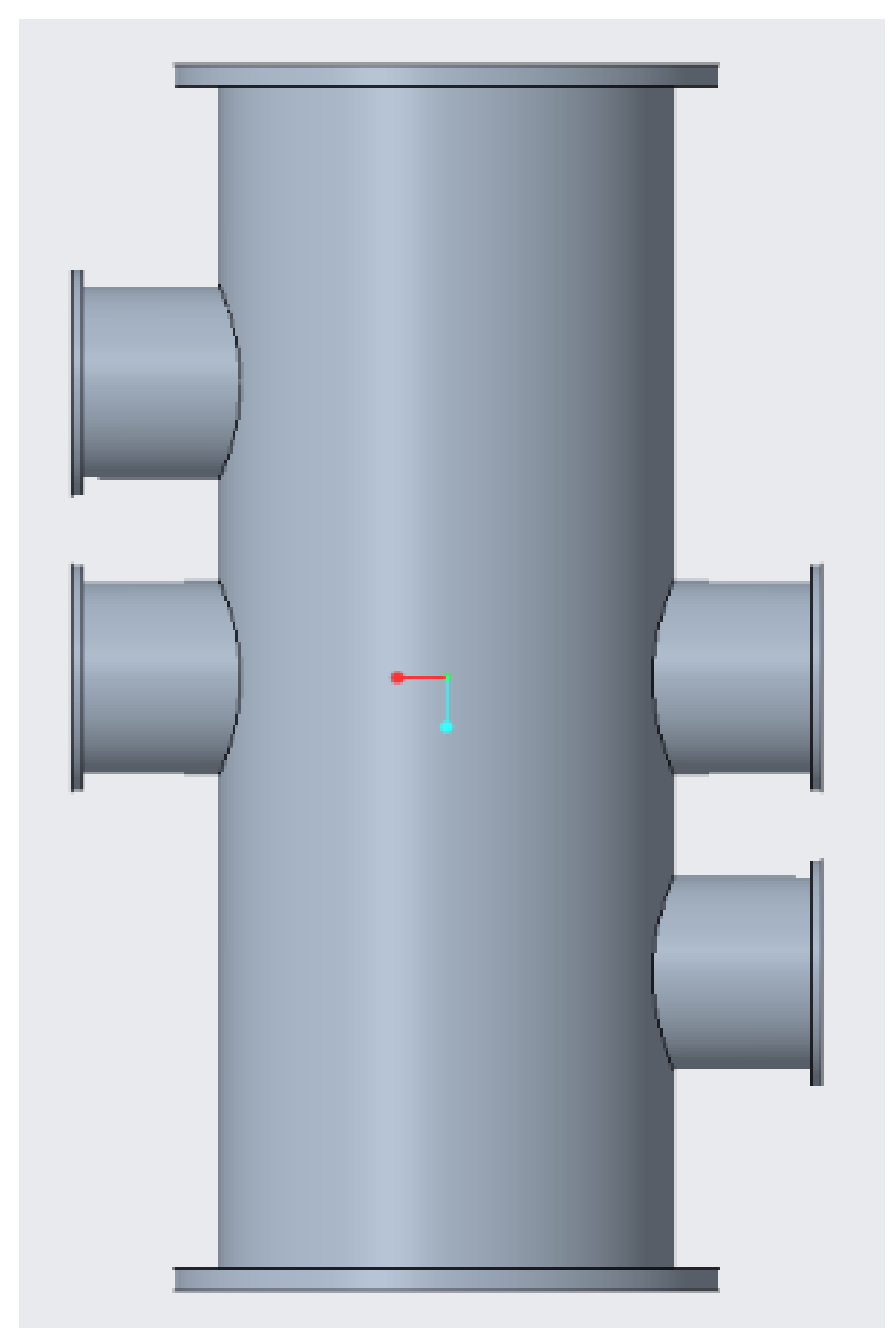

Figure 13. View of main chamber showing viewports.

The upper chamber section will contain 12 side ports equally spaced circumferentially (see Figure 14). The ports will be designed and utilized according to:

- 1 Port/flange for power feedthrough to power heater to simulate decay heat (reference feedthrough requires adapting from 2.75 " CF to 1.33 " CF)

- 5 port/flange for thermocouple feedthroughs (reference feedthrough 2.75 " CF)

- 1 port/flange for siphon tube; gas injected through this port during recirculation; gas is removed through this port during vacuum drying; this connection is isolated with a valve that connects to the Holtec drying system

- 1 port/flange for vent; to accommodate recirculation; will contain two crosses for pressure sensor connection adjacent to the chamber and terminated with a valve to isolate the chamber and connect to the Holtec drying system

- 1 port/flange for relative humidity probe (2.75" CF with adaptor for $1 / 2$ " NPT)

- Needed in particular for vacuum drying tests

- 1 port/flange for OES; adapt to $1 / 4$ " Swagelok tubing with isolation valve

- 2 port/flange (vacant for future use). 


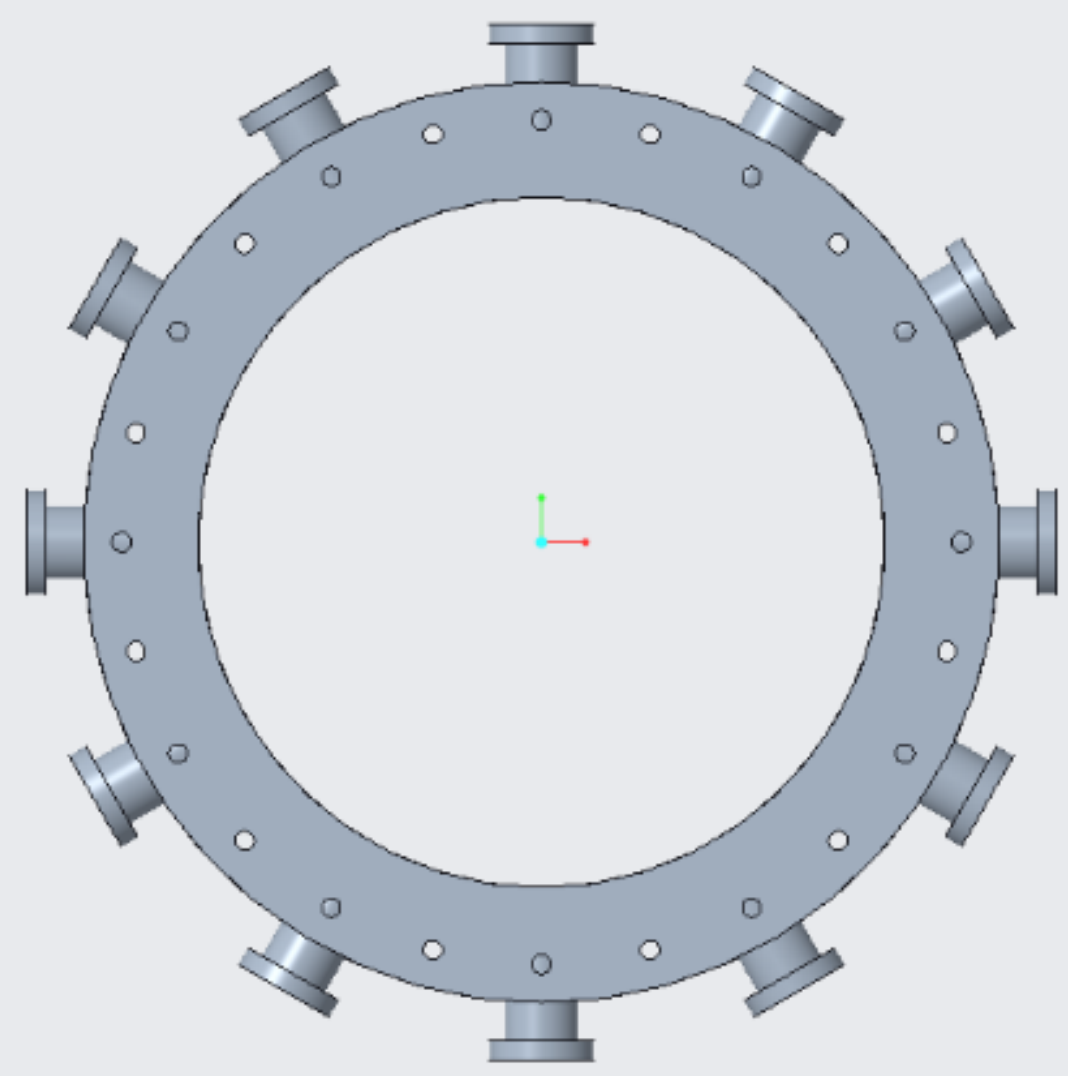

Figure 14. Top view of upper chamber section showing 12 viewports each with a 2.75 " CF flange.

\subsection{Basket}

The installed basket will reproduce the dimensions of the Type 1A Basket design holding 10 ASNF mock assemblies (see Figure 3). This will have a 16.9" (42.93 cm) outer diameter and be 51" (129.54 $\mathrm{cm}$ ) tall. Semicircular (mouse hole) cut outs at bottom will be used to promote cross flow between cells (see Figure 1b). An alternative design with a false bottom to better distribute hot helium gas in recirculation was previously shown in Figure 1c. The traditional basket has one or more half inch diameter holes through the basket plates to allow for cross flow. These are not used in the present design. The idea of baffling or alternating height of the different plates to better redistribute flow at the top of the chamber was dropped considering that the plenum space in the chamber will be larger to accommodate instrumentation and wiring needed for the experiments.

\subsection{Siphon Tube}

The siphon tube is a $3 / 4$ " OD stainless steel pipe that runs from one of the ports at the top of the chamber to the bottom of the chamber. A small clearance at the bottom of $0.1 "(0.254 \mathrm{~cm})$ is used in models but "mouse hole" cutouts are used to ensure flow is not obstructed even if it were to sit on the bottom of the chamber. A $3 / 4$ ", 90degree pipe elbow allows it to be installed once the upper chamber section is in place. It is to be located in an unobstructed location in the outer edge basket cell (i.e. still allow 10 assemblies in 1A Basket), see Figure 3. Holtec experience is to blow/inject through the siphon tube rather than evacuate through siphon tube as typical with vacuum drying. The vent connection should be made to the port/flange that is opposite the siphon tube to promote greater mixing and distribution among the cells of the basket. 


\subsection{Mock Fuel Assembly}

The mock ASNF assemblies are to be fabricated from bolted plates of 6061 aluminum sheet metal (simplified view Figure 2). Spacers at each edge will provide the proper gap between plates. For plates, aluminum sheet metal with 16-gauge 6061 aluminum, $0.05082 "(0.1291 \mathrm{~cm})$ thick compares well to ATR/ASNF plates at $0.05 "(0.127 \mathrm{~cm})$ thick. Spacers located between sheets at edges to effect the plate gap can be fabricated from 12-gauge 6061 aluminum $(0.08081$ " or $0.2053 \mathrm{~cm}$ thick) which compares with the actual ATR/ASNF gap of 0.078 " $(0.1981 \mathrm{~cm})$. The plate height will be 49 " $(124.5 \mathrm{~cm})$ while spacer height will be 49.5 " $(125.7 \mathrm{~cm})$ to promote circulation underneath the assembly (ATR fuel plates are 49.5 " in height). Four of the plates will be "stiffened" with a 90-degree bend at the edge of the assembly to promote rigidity of the assembly and simulate the side panels of ATR/ASNF fuel assemblies. These stiffened plates will be fabricated from 5052, 16-gauge aluminum and be 50 " $(127 \mathrm{~cm})$ in height. The width of mock fuel plates will be $3.15 "(8.001 \mathrm{~cm})$ with 20 plates total including stiffened plates. Accounting only for the 20 plates, the surface area and volume approximates that of an ATR/ASNF assembly with approximate surface area of $42.9 \mathrm{ft} 2(39,830 \mathrm{~cm} 2)$ compared with $43.32 \mathrm{ft} 2(40,250 \mathrm{~cm} 2)$ for ATR/ASNF and metal volume of $156.9 \mathrm{in} 3(2571 \mathrm{~cm} 3)$ compared with ATR/ASNF with approximately $170 \mathrm{in} 3(2786 \mathrm{~cm} 3)$. This does not account for spacers and bolts in the mock fuel assembly.

\subsection{Heating Elements}

Heating elements (Figure 15) to simulate decay heat for ASNF will be implemented in one assembly (\#4 in Figure 3). The goal is to evaluate the impact (add effect) of decay heat on drying. This assembly will be one to also have a chemically treated sheet to facilitate comparison with the non-heated assembly.

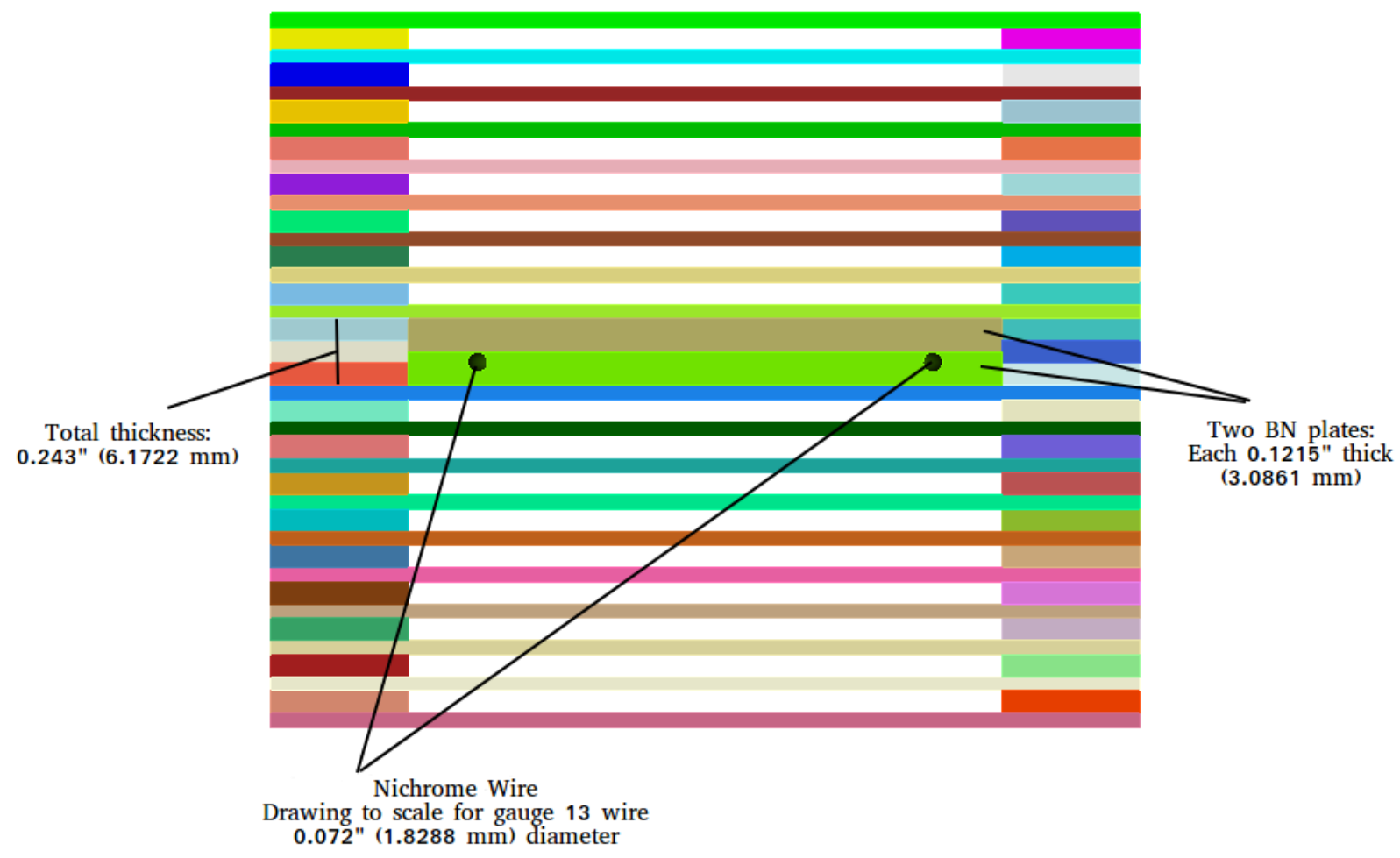

Figure 15. Mock ASNF design shown with a heating element to simulate decay heat. The coloring is attributable to meshing program. Drawing is to scale for gauge 13 (0.072" diameter) nichrome wire. 
The heating element design will permit testing over varying simulated heat loads from $10 \mathrm{~W}$ to $100 \mathrm{~W}$. The design utilizes a nichrome wire for resistance heating. The nichrome will be looped between two sheets of boron nitride (BN) that are themselves sandwiched between two aluminum plates of the assembly. This particular assembly will have one less aluminum plate so the total thickness of the heating element will be the width of two gaps and one aluminum plate (see Figure 15). Boron nitride is used because it is a good dielectric that is thermally conductive and also machinable. The ability to machine $\mathrm{BN}$ is important to be able to machine grooves for the nichrome wire to follow in one of the $\mathrm{BN}$ sheets before assembly. BN sheets can be purchased in varying thicknesses and lengths. Quotes were obtained for lengths of 17" $(43.18 \mathrm{~cm})$ allowing the sheets to be stacked on top of each other in the process of assembling the mock fuel assembly. Looping of the nichrome wire in this manner will yield approximately 8 feet of wire.

To implement this design, a power feedthrough, power transducer, and power supply will be required. For the low power control needed here (i.e. to produce $10 \mathrm{~W}$ att to $100 \mathrm{Watt}$ per assembly) and using suggested gauge wire: AWG13, AWG14, AWG15, AWG16, or AWG17, a range of current is required varying from $2 \mathrm{~A}$ to $10 \mathrm{~A}$ and voltage of $3 \mathrm{~V}$ to $16.5 \mathrm{~V}$ based on wire gauge and current/power. A suggested power supply, Keysight Technologies N8741A, can yield DC output of 300V, 11A, and power of $3300 \mathrm{~W}$. Precision of this model varies as $0.05 \%+150 \mathrm{mV}$ and $0.1 \%+22 \mathrm{~mA}$. A reference power feedthrough, A0266-3-CF (Apex Vacuum), has multipin capability in case it is later desired to heat other assemblies or split heating of an assembly into multiple heating elements/zones. The model A0266-3-CF power feedthrough is capable of 500 Volts and 15 Amps and has 8 Pins each with diameter 0.032" copper conductors. It requires adapting the port flange from $2.75^{\prime \prime} \mathrm{CF}$ to $1.33^{\prime \prime} \mathrm{CF}$ but only for the port used for this power feedthrough.

\section{MATERIALS \\ 4.1 Chemically Treated Plates}

ASNF plates will be chemically treated to produce surfaces with aluminum hydroxides to reproduce the effects of chemisorbed water. Depending on treatment and handling, surfaces with varying layer thickness and with varying chemical form of Gibbsite and/or Boehmite can be formed yielding varying amounts of hydroxide units. Based on surrogates produced in different laboratories, a reference thickness of 10um is given. For the proposed Engineering Scale Design, four assemblies per experiment will receive chemically treated plates (ref. Figure 16):

- 1 on hottest assembly (\#10)

- 1 on coldest (\#1)

- 1 on (\#4) heated assembly

- 1 on (\#7) a mid-range temperature assembly (non-heated).

This arrangement keeps treated assemblies approximately in a line across the chamber diameter. The chemically treated plates will have a length/height of 12 "' $(30.48 \mathrm{~cm})$ and will be treated on both sides (see Figure 16). For reference, a full length treated sheet that is full height, treated on both sides, with a 10 um thick oxide layer, that is $50 \%$ porosity of that oxide layer would yield if Boehmite, $460 \mathrm{mg}$ water, or if Gibbsite, $860 \mathrm{mg}$ water. Actual treated plates would likely have a combination of these and with varying thickness and porosity. Therefore, a likely upper limit on chemisorbed water for a chamber of this size would be approximately 9 grams. 


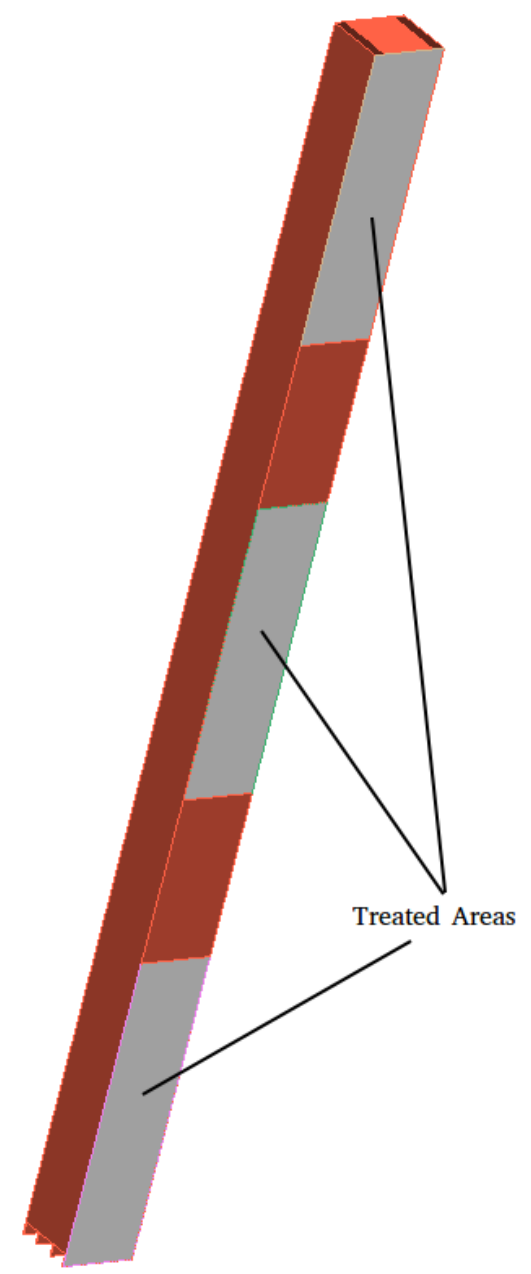

Figure 16. Sketch of mock ASNF assembly showing suggested locations of chemically treated plates with oxide layers. Note this is to scale assuming treated panels are 12" in height/length.

\subsection{Physisorbed Water}

ASNF plates would contain a certain amount of physiosorbed water. Assuming the physisorbed water to be less than the chemisorbed water, then 9 grams would be an expected upper limit for a chamber of this size with 10 ASNF assemblies.

\subsection{Bulk Water}

Some ASNF assemblies would be loaded directly from the spent fuel pool in a condition that is described as "drip dry". This would contribute bulk water to the chamber that would be removed during drying tests. Side viewports or an available port in the top chamber section permits the addition of a known amount of water before the start of a test. By varying this amount of water, the impact of bulk water on drying time and condition can be evaluated.

\subsection{Debris/"Mud"}

Some ASNF assemblies are housed in facilities with open air access enabling debris, dust, or dirt to collect at the bottom of pools and become trapped or held between ASNF plates. This debris will be waterlogged and has been termed "mud" in some reporting. Earlier efforts have simulated this debris or "mud" as it has been called using different clay materials. This work does not seek to simulate this debris given that it is not applicable to a wide range of ASNF assemblies. 


\section{INSTRUMENTATION}

\subsection{Temperature Measurement}

Temperature measurement inside the chamber will be accomplished through the use of thermocouples joined to the ASNF assemblies and basket. Type K thermocouples can measure temperatures up to about $800^{\circ} \mathrm{C}$. The type with glass braid insulation can withstand temperatures as high as $482^{\circ} \mathrm{C}$. The same four assemblies bearing chemically altered sheets will be instrumented (assemblies 1, 4, 7, 10). Placement will be five thermocouples axially along the outer surface and five internally between two of the plates. It is noted that when attaching thermocouples, a bead of sterling silver is recommended to avoid a brittle joint. Thermocouples will be placed on the basket and siphon tube in both expected hotter and colder regions as noted below. A total of 50 thermocouples will be placed as summarized below:

- 10 each on 4 assemblies (\#1, 4, 7, 10)

○ 5 TC axially on outer surface

- 5 TC axially on internal sheet

- 4 TC axially on basket at corner between assemblies 8 and 10

- 4 TC axially on basket at corner between assemblies 1 and 3

- 2 TC axially on siphon tube (top, bottom).

The use of thermocouples in the chamber requires available type $\mathrm{K}$ feedthroughs (A0206-1-CF) which can accommodate 10 pair per feedthrough so a total of five feedthroughs is required. These are available in a 2.75 " CF flange to match the port connections on chamber upper section.

Depending on availability of gas temperature measurement in the Holtec drying network to be attached to the chamber, inline gas measurement is available in a module (LACO Technologies) that can attach at the entrance and exit of the chamber. A measure of the gas temperature is needed for model validation. This inline gas temperature measurement uses a suspended type K thermocouple. Modules also have the ability to be heated to raise the gas temperature further is desired and also to reduce losses around the entrance/exit of the chamber. Other options such as fiber optic temperature measurement was investigated but determined to not be as useful and more difficult to implement in the chamber. Viewports are available on the main chamber section as noted above. These permit the use of thermal imaging if later determined to be necessary. Available instruments include FLIR A325sc with spectral range of the is 7.5-13um. ZnSe viewports are used to pass LongWaveIR between 0.3-17um to the thermal camera.

Thermocouples (type K) will be place on the outside of the chamber to provide additional data for model validation and understand heat losses and the effect of different environmental conditions on the drying operation. A total of 20 thermocouples are specified with five axially arranged in four columns spaced at 90 degrees around the outside of the chamber.

\subsection{Relative Humidity}

In addition to the instrumentation available on the Holtec gas recirculation network specifically, chilled mirror and dew point measurement, additional instrumentation will be required for the chamber.

A relative humidity probe, Vaisala HMT 334, capable of high temperature operation will be installed at one of the viewport locations at the upper chamber section. This is particularly needed for vacuum drying tests where the chamber will be isolated. 


\subsection{Optical Emission Spectroscopy}

This instrument involves a direct current (DC) driven plasma discharge and optical emission spectroscopy (OES) for detecting as well as quantifying water vapor in a flowing gas stream under both trace and high-water vapor loading conditions. For the quantification of water content, a system has been calibrated for gas mixtures of helium and water vapor (Tahiyat, 2018). The OES system is connected to the chamber via a 0.25 " $(0.635 \mathrm{~cm})$ stainless steel tube and Swagelok connection from one of the 2.75 " $\mathrm{CF}$ ports on the upper section of the chamber. A valve isolates the system from the chamber except for times when a sample is being drawn for measurement. During measurement, the valve is opened and a sample gas stream is drawn from the chamber from a mechanical vacuum pump downstream of the OES.

\subsection{Pressure Measurement}

Pressure measurements are taken in the Holtec drying network. Pressure measurement directly on the chamber is required for both forced helium drying and vacuum drying operations. Four pressure gauges (Table 5) are attached to the vent port through two crosses as indicated in Figure 17. Low pressure sensors are needed for vacuum drying while higher pressure sensors are needed for forced helium drying. Low pressure sensors must be able to be valved off separately from the chamber during higher pressure operations such as forced helium drying. Just downstream of the pressure sensors, the vent line can be closed off to isolate the chamber.

Table 5. Instruments to be used in data collection during drying tests shown with operating range and uncertainty.

\begin{tabular}{|c|c|c|c|c|}
\hline Sensor & $\begin{array}{c}\text { Manufacturer } \\
\text { /Part\# }\end{array}$ & Range & $\begin{array}{c}\text { Operating } \\
\text { parameters }\end{array}$ & Uncertainty \\
\hline $\begin{array}{c}\text { Thermocouple } \\
\text { (K-Type) }\end{array}$ & $\begin{array}{c}\text { Apex/ } \\
\text { Schoonover }\end{array}$ & $-50-800{ }^{\circ} \mathrm{C}$ & $-50-800^{\circ} \mathrm{C}$ & $0.75 \%$ of range \\
\hline $\begin{array}{l}\text { Humidity } \\
\text { transmitter }\end{array}$ & $\begin{array}{l}\text { Vaisala } \\
\text { HMT334 }\end{array}$ & $0-100 \% \mathrm{RH}$ & $\begin{array}{l}\text { at }+15 \ldots+25^{\circ} \mathrm{C} \\
\text { at }-20 \ldots+40^{\circ} \mathrm{C} \\
\text { at }-40 \ldots+180^{\circ} \mathrm{C}\end{array}$ & $\begin{array}{c}1 \% \mathrm{RH}(0 \ldots 90 \%) \\
\pm 1.7 \% \mathrm{RH}(90 \ldots \\
100 \% \mathrm{RH}) \\
\pm(1.0+0.008 \mathrm{x} \\
\text { reading } \% \mathrm{RH} \\
\pm(1.5+0.015 \mathrm{x} \\
\text { reading } \% \mathrm{RH} \\
\end{array}$ \\
\hline $\begin{array}{c}\text { (P1) Pressure } \\
\text { transducer } \\
\text { (high temperature) }\end{array}$ & MKS 628F & $\begin{array}{c}0-2000 \text { Torr } \\
\text { (2400 Torr over } \\
\text { pressure) }\end{array}$ & $15-50^{\circ} \mathrm{C}$ & $0.25 \%$ of reading \\
\hline $\begin{array}{c}\text { (P2) Pressure } \\
\text { transducer } \\
\text { (low temperature, } \\
\text { high pressure) }\end{array}$ & MKS 722B & $\begin{array}{c}0-2000 \text { Torr } \\
\text { (4000 Torr over } \\
\text { pressure) }\end{array}$ & $0-50^{\circ} \mathrm{C}$ & $0.5 \%$ of reading \\
\hline $\begin{array}{c}\text { (P3) Pressure } \\
\text { transducer } \\
\text { (low temperature, } \\
\text { low pressure) }\end{array}$ & MKS 902B & $\begin{array}{c}0-1000 \text { Torr } \\
(1500 \text { Torr over } \\
\text { pressure })\end{array}$ & $0-40^{\circ} \mathrm{C}$ & $1 \%$ of reading \\
\hline $\begin{array}{c}\text { (P4) Pressure } \\
\text { transducer } \\
\text { High pressure, high } \\
\text { temperature }\end{array}$ & $\begin{array}{l}\text { Omega } \\
\text { PX1009L0- } \\
\text { 100AV }\end{array}$ & 0 to $100 \mathrm{psi}$ & $\begin{array}{l}-54 \text { to } 343^{\circ} \mathrm{C} \\
\left(-65 \text { to } 650^{\circ} \mathrm{F}\right.\end{array}$ & $\begin{array}{l}\text { Accuracy: Combined } \\
\text { linearity, hysteresis } \\
\text { and repeatability: } \\
\pm 0.25 \% \text { FSO, BSL } \\
\text { (over the } \\
\text { compensated } \\
\text { temperature range) }\end{array}$ \\
\hline
\end{tabular}




\section{Vacuum Chamber Connections}

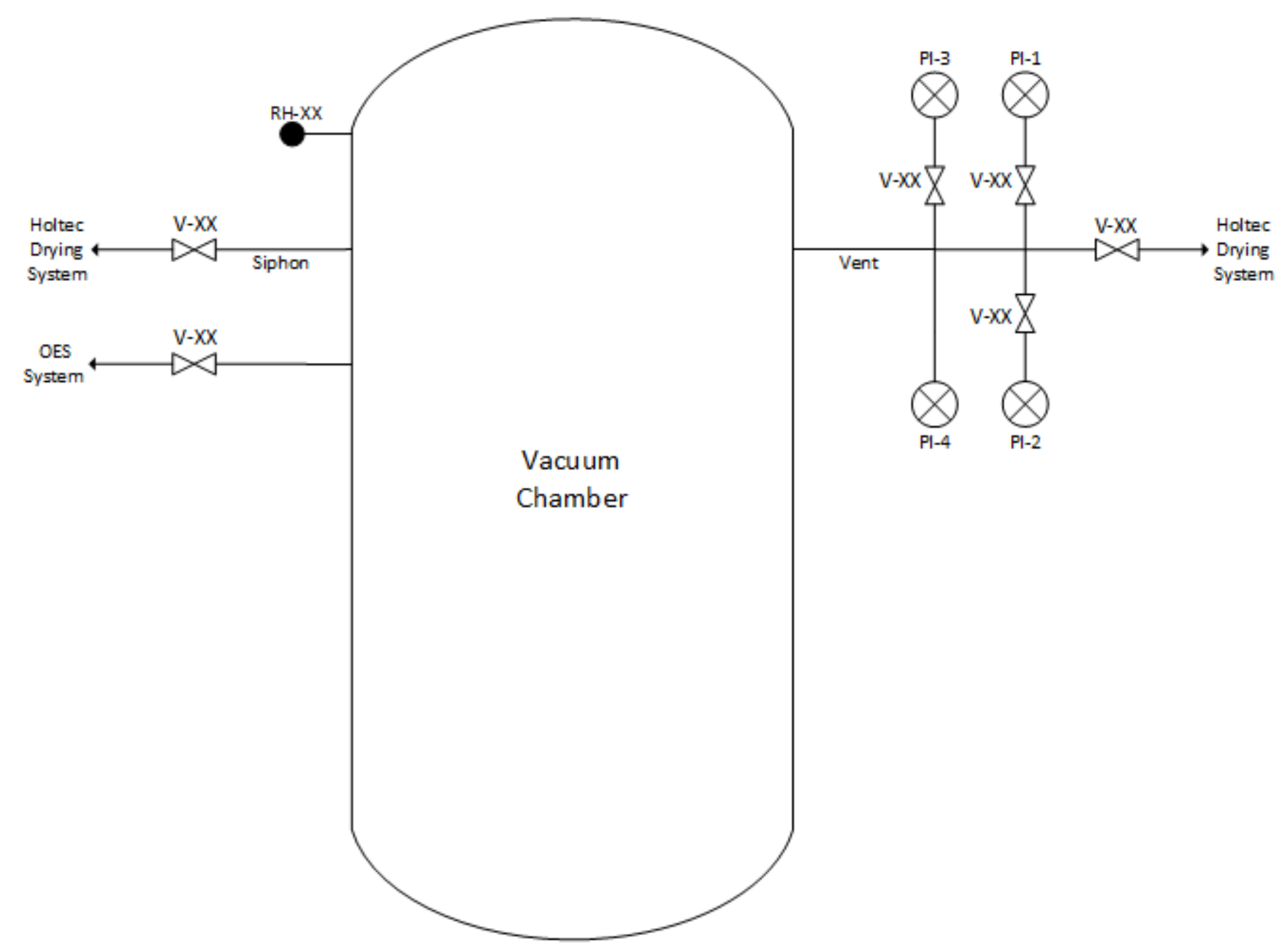

Figure 17. Schematic of the test chamber showing connections and connection design. 


\subsection{Flow Rate Measurement}

Experience shows that flow meters are too restrictive for vacuum drying operations in the long piping network. FHD experiments with higher pressure and substantial flow rates will make use of the existing equipment in the Holtec drying system.

\subsection{Data Acquisition System}

Data collection and heater control will be performed by a central computing hub such as the National Instruments PXI platform. A PXIe-8840 Chassis (8-slot) with integrated controller running Windows 10 would be applicable along with supporting hardware cards including Analog Input, Analog Output, 3 Thermocouple Inputs, and a Multifunction DAQ (NI-PXI 4302, 4322, 4353, \& 6341 respectively). Such a setup would accommodate 2 FLIR thermal cameras via the controllers 2 ethernet ports, control of up to 8 heating elements, and data collection from a combination of up to 16 Analog signals (Relative Humidity \& Pressure), up to 24 Digital I/O signals, and up to 96 thermocouples. Additional ethernet cards (8234) could be purchased for accommodating more thermal cameras and a Relay Driver Module (2567) would permit pneumatic valve control (ON/OFF) for up to 64 valves.

\section{EXPERIMENT DESIGN}

As noted earlier, the reference maximum drying temperature is $250^{\circ} \mathrm{C}$ based on material concerns. Preliminary studies suggest slightly higher temperatures of $260^{\circ} \mathrm{C}$ are more effective at achieving the desired Gibbsite to Boehmite transition with concomitant loss of water. Based on even more recent experiments with coupon specimens using thermogravimetric analysis (TGA), the expected time to nearly complete this transformation after reaching this temperature is about 4 hours.

\subsection{Forced Helium Drying Tests}

A target temperature of $220^{\circ} \mathrm{C}$ will be evaluated in forced helium drying tests. A recommended drying time of 8 hours is also projected based on this lower temperature. The recommended approach is to assess the chemically treated plates after this drying time and temperature and propose one shorter and one longer drying times to evaluate the rate of transformation (loss of water) in the engineering scale experiment. The motivation is then to use this information in modeling and also to evaluate tradeoff between time (schedule and faster throughput) and degree of drying (tolerable residual water). A fourth experiment is proposed to evaluate higher temperature (recommend $260^{\circ} \mathrm{C}$ ) with a shorter drying time (recommend 4 hours). A fifth experiment can be anticipated to fulfill the need for data for model validation. Parameters for this test are to be determined from evaluations of the forgoing tests. The required number of chemically treated panels (partial plates) is thus 3 per assembly $\mathrm{x} 4$ assembly per test $\mathrm{x} 5$ tests $=60$ panels. The proposed Test Plan is summarized in Table 6 . If repeat tests are required for confirmation, additional sheets will be required accordingly.

Test cases 1 to 5 shown in Table 6 are considered to be the original or base test cases for FHD involving original as produced chemically treated plates. After each original/base test has been conducted, a sampling of the chemically treated plates will be removed and samples cutaway for characterization. A sampling of the untreated plates that have now undergone testing will also be characterized to understand the impact testing has on the evolving condition of the assemblies used in testing. The plates will be returned to the assemblies (minus coupons taken for characterization). Following the base tests with original as produced chemically treated plates, a second series of tests will be conducted with a larger amount of bulk water added to evaluate the impact of bulk water on drying. The bulk water added in these experiments simulates the bulk water transferred to the canister in loading assemblies in a "drip dry" condition. Other repeat tests with previously tested chemically treated plates may be conducted to evaluate the effects of extended drying operations. 
Table 6. Test cases proposed for forced helium drying evaluation.

\begin{tabular}{|l|l|l|}
\hline Base Test Case & Target Temperature & $\begin{array}{l}\text { Drying Time (after reaching } \\
\text { target temperature) }\end{array}$ \\
\hline 1 & Reference $\left(220^{\circ} \mathrm{C}\right)$ & Reference $(8 \mathrm{hr})$ \\
\hline 2 & Reference $\left(220^{\circ} \mathrm{C}\right)$ & Shorter time $(6 \mathrm{hr})^{*}$ \\
\hline 3 & Reference $\left(220^{\circ} \mathrm{C}\right)$ & Longer time $(12 \mathrm{hr})^{*}$ \\
\hline 4 & Higher temperature $\left(260^{\circ} \mathrm{C}\right)^{* *}$ & Shorter time $(4 \mathrm{hr})^{*}$ \\
\hline 5 & Added Test*** & Added Test*** \\
\hline $\begin{array}{l}\text { 1A with larger amount of bulk } \\
\text { water }\end{array}$ & Reference $\left(220^{\circ} \mathrm{C}\right)$ & Reference $(8 \mathrm{hr})$ \\
\hline $\begin{array}{l}\text { 4A with larger amount of bulk } \\
\text { water }\end{array}$ & $\begin{array}{l}\text { Higher temperature used in test } \\
4\end{array}$ & Shorter time $(4 \mathrm{hr})^{*}$ \\
\hline
\end{tabular}

* precise time to be informed by initial results of baseline/reference test; ** based on evaluation of the drying system material limitations; $* * *$ based on evaluation of results of earlier tests.

\subsection{Vacuum Drying Tests}

Data A series of vacuum drying tests will be conducted. These tests will follow customary industry practice of isolation holds once achieving different vacuum levels as noted in Table 7. During the isolation holds the chamber is isolated from the vacuum pump and piping network. The pressure rise is monitored to determine if the test can proceed to the next step (see Table 7).

Table 7. Isolation holds in vacuum drying tests and criteria to proceed to next vacuum step.

\begin{tabular}{|l|l|l|}
$\begin{array}{l}\text { Vacuum } \\
\text { Step, Hold } \\
\text { Pressure }\end{array}$ & Hold Time & $\begin{array}{l}\text { Criteria to } \\
\text { Proceed to Next } \\
\text { Step }\end{array}$ \\
\hline$<\mathbf{5 0}$ torr & $5 \mathrm{~min}$. & $<100$ torr \\
\hline$<\mathbf{2 5}$ torr & $5 \mathrm{~min}$. & $<50$ torr \\
\hline$<\mathbf{1 5}$ torr & $5 \mathrm{~min}$. & $<25$ torr \\
\hline$<\mathbf{1 0}$ torr & $5 \mathrm{~min}$. & $<15$ torr \\
\hline$<5$ torr & $5 \mathrm{~min}$. & $<10$ torr \\
\hline$<3$ torr & $5 \mathrm{~min}$. & $<5$ torr \\
\hline$<2$ torr & $30 \mathrm{~min}$. & $<2.6$ torr \\
\hline
\end{tabular}

For For vacuum drying, the temperature of the assembly will be more controlled by the heating tape and insulation surrounding the chamber. Recognizing the relatively modest decay heat of the ASNF assemblies, the setpoint of the heating tape should be increased to $150^{\circ} \mathrm{C}$ with the beginning of the experiment. The lower temperatures likely encountered in the vacuum drying would be expected to result 
in less chemisorbed water loss where again the most significant phase transformation in the aluminum hydroxides have been noted to occur at temperatures of approximately $260^{\circ} \mathrm{C}$. Test cases for vacuum drying evaluation are indicated in Table 8.

Table 8. Test cases proposed for vacuum drying evaluation.

\begin{tabular}{|l|l|l|l|}
\hline Number & Test & Heating Tape & Holds \\
\hline 1 & Baseline test & $150^{\circ} \mathrm{C}$ setpoint, & Regular holds \\
\hline 2 & Greater heating from external & $220^{\circ} \mathrm{C}$ setpoint, & Regular holds \\
\hline 3 & Extended hold time & $150^{\circ} \mathrm{C}$ setpoint, & Extended $(\mathrm{x} 4)$ \\
\hline 4 & $\begin{array}{l}\text { Added test based on feedback from } \\
\text { earlier tests }\end{array}$ & TBD & TBD \\
\hline
\end{tabular}

With vacuum drying and low decay heat, ice formation is possible. However, the loading of the ASNF assemblies in a "drip dry" condition compared to underwater loading of commercial spent fuel assemblies, means the ASNF canister will have only a very limited amount of bulk water to be of concern for ice formation. Still, to monitor for this a flat surface analogous to a spacer disc in some commercial spent fuel canisters will be placed in view of the viewport and thermal camera. This simulated spacer disc is capable of holding several to perhaps $25 \mathrm{ml}$ of water. Information to be collected here provides indication of possible freezing of any bulk water in the canister which may have the potential to be collected in other areas such as the bottom of the canister but not as accessible to observation. The length of the isolation holds also plays a role in mitigating ice formation (if present). Longer holds provide for greater heat transfer from surroundings and has the potential to reduce or eliminate ice that may form during a vacuum step.

\subsection{Characterization}

Recent studies of water loss and phase transformation among simulated ASNF plates, has made use of SEM, XRD, and TGA to characterize samples before and after tests. SEM of surface have been able to show the morphology which provides some indication of the phase(s) present and an estimate of the hydroxide layer thickness. XRD has been able to reveal at least the predominant phase(s) present. TGA studies have been able to reveal the threshold temperatures for the onset of phase transformation and the amounts of water that can be removed in a given time period or examined another way the time required to complete a transformation with concomitant water loss at a given temperature.

Characterization of five random samples is recommended prior to testing in order to understand the original as-received surrogate ASNF plate surfaces. As performed in earlier studies, this would provide indication of phases present, likely layer thicknesses, and the amount of water present (and lost) for each of the phases present where transformations occur.

At least two samples are recommended to be characterized from each test (including tests from both FHD and vacuum). These should be taken from the hottest region observed (expected to be on the heated assembly) and the coldest region observed. Additional samples could be characterized by SEM to better understand how consistent the results are across the canister and at different locations. The TGA studies are limiting in the time involved (up to 30 hours). 


\section{REFERENCES}

Abboud, Alexander, and Hai Huang, "Transient Coupled Chemical-Thermal-Fluid Field Simulation for Sealed Aluminum-clad Spent Nuclear Fuel Storage Canister," INL/EXT-18-51683, Rev. 0, June 2018.

Abboud, Alexander, and Hai Huang, "Development of Transient Coupled Chemical-Thermal-Fluid Multiphysics Simulation for Unsealed, Vented Aluminum-clad Spent Nuclear Fuel Storage Canister," INL/EXT-18-51681, Rev. 0, September 2018.

Smith, Rebecca E., “Aluminum Clad Spent Nuclear Fuel Task 5: Oxide Layer Response to Drying Experiment Test Plan,” INL/EXT-19-54019, Rev. 1, August 2019.

Snow, Spencer D., "Design Considerations for the Standardized DOE SNF Canister Internals, National Spent Nuclear Fuel Program,” DOE/SNF/DSN-019, Rev.1, March 2008.

Tahiyat, Malik, Travis W. Knight, and Tanvir Farouk, "Plasma optical emission spectroscopy for water vapor quantification and detection during vacuum drying process," Review of Scientific Instruments, 89, 116108 (2018); doi: 10.1063/1.5047210. 